\title{
Unplugging or Staying Connected? Examining the Nature, Antecedents, and Consequences of Profiles of Daily Recovery Experiences
}

\author{
Nitya Chawla \\ Department of Management and Organizations \\ University of Arizona \\ 1130 E. Helen Street, McClelland Hall 405 \\ Tucson, AZ 85721-0108 \\ Phone: 520.621 .3583 \\ Email: nityac@email.arizona.edu \\ Rebecca L. MacGowan \\ Department of Management and Organizations \\ University of Arizona \\ 1130 E. Helen Street, McClelland Hall 405 \\ Tucson, AZ 85721-0108 \\ Phone: 520.621 .3583 \\ Email: rlmacgowan@email.arizona.edu \\ Allison S. Gabriel \\ Department of Management and Organizations \\ University of Arizona \\ 1130 E. Helen Street, McClelland Hall 405 \\ Tucson, AZ 85721-0108 \\ Phone: 520.621.1390 \\ Email: asgabriel@email.arizona.edu \\ Nathan P. Podsakoff \\ Department of Management and Organizations \\ University of Arizona \\ 1130 E. Helen Street, McClelland Hall 405 \\ Tucson, AZ 85721-0108 \\ Phone: 520.626.0463 \\ Email: podsakof@email.arizona.edu
}

Note. A previous version of this paper was presented at the 2018 Annual Conference of the Academy of Management in Chicago, IL and the 2019 Annual Conference of the Society for Industrial and Organizational Psychology in Washington, DC. This research was supported by funding from the Center for Leadership Ethics, Eller College of Management and the Eller College of Management Small Research Grants. Correspondence should be directed to Nitya Chawla, Department of Management and Organizations, Eller College of Management, University of Arizona; email: nityac@email.arizona.edu. 
Unplugging or Staying Connected? Examining the Nature, Antecedents, and Consequences of Profiles of Daily Recovery Experiences 


\begin{abstract}
Research on workplace recovery recognizes that employees must restore lost resources after work in order to improve their subsequent well-being and performance. Scholars have also noted that employees' recovery experiences_-psychological detachment, relaxation, mastery, and control—vary day-to-day, yielding crucial implications for the aforementioned outcomes. Yet, despite these important theoretical and empirical insights, researchers to date have not comprehensively examined multiple daily recovery experiences in conjunction, instead studying the unique effects of only one or two experiences in isolation. Using a person-centric view of employees' recovery experiences, the current study examines whether profiles of daily recovery experiences occur for employees, and how these profiles (a) vary in membership from one day to the next, (b) are differentiated by daily job demands and resources experienced at work, and (c) predict employee well-being and discretionary behaviors during the subsequent workday. Using experience sampling data from 207 full-time employees, results revealed five profiles of daily recovery experiences that exhibited distinct relations with within-person antecedents and outcomes. As such, the current investigation represents a necessary first step in understanding how employees jointly experience recovery in relation to their daily work and well-being.
\end{abstract}

Keywords: recovery; well-being; discretionary behaviors; latent profile analysis; experience sampling methods 
On a daily basis, employees are faced with a variety of job and work-related demands that take a psychological toll, requiring them to expend substantial effort and energy to perform effectively (Meijman \& Mulder, 1998). However, exerting effort often depletes employees’ psychological resources and increases strain, both of which can hinder well-being and performance (Meijman \& Mulder, 1998; Sonnentag \& Natter, 2004). To avoid such impairments, employees must replenish, recuperate, and recover lost resources, particularly during time after work (Sonnentag, 2001; Sonnentag \& Natter, 2004; Zijlstra \& Sonnentag, 2006). Recovery, therefore, refers to the process through which employees alleviate the detrimental effects of work stressors through restorative experiences (Sonnentag \& Fritz, 2007; Sonnentag \& Natter, 2004).

Since Sonnentag's (2001) seminal work on recovery, scholarship has demonstrated that post-work recovery positively affects employees’ well-being, experiences, and workplace behaviors (Demerouti, Bakker, Sonnentag, \& Fullagar, 2012; Sonnentag, 2003; Sonnentag, Venz, \& Casper, 2017). Typically, researchers have focused on four recovery experiences (Sonnentag \& Fritz, 2007): psychological detachment (i.e., not thinking about work issues); relaxation (i.e., taking time for leisure); mastery (i.e., learning new things); and control (i.e., having control over one's leisure time). Most scholars studying recovery have adopted a variable-centered approach (Wang \& Hanges, 2011), examining the separate, unique effects of each experience in isolation, ignoring the possibility that multiple post-work recovery experiences may occur for employees simultaneously (e.g., experiencing both high psychological detachment and relaxation; Folkman, Lazarus, Gruen, \& DeLongis, 1986). One stream of work, however, has begun to challenge this assumption by adopting a person-centered perspective (Wang \& Hanges, 2011) in studying employee recovery. For instance, Siltaloppi, Kinnunen, Feldt, and Tolvanen (2011) explored employees' recovery experiences over one year, finding 
that they varied in their conjoint use of recovery experiences over time. Recently, Bennett, Gabriel, Calderwood, Dahling, and Trougakos (2016) demonstrated that employees report having recovery experiences occur in conjunction; across two studies, these authors found three unique profiles of employees who differed in their combined use of recovery experiences.

Despite the insights gained through these studies, both Siltaloppi et al. (2011) and Bennett et al. (2016) focused on general recovery tendencies. This departs from the literature demonstrating that employees' recovery experiences fluctuate daily (e.g., Derks, van Mierlo, \& Schmitz, 2014; Sonnentag \& Bayer, 2005; Volmer, Binnewies, Sonnentag, \& Niessen, 2012) and that substantial variance in recovery experiences is attributable to within-person factors (e.g., Bono, Glomb, Shen, Kim, \& Koch, 2013; Podsakoff, Spoelma, Chawla, \& Gabriel, 2019). As such, the recovery literature still lacks a comprehensive theoretical and empirical understanding of the combinations of recovery experiences that employees have on a daily basis, as well as the factors (e.g., job demands or resources) influencing day-to-day changes in these combinations. In light of the potential mismatch between prior person-centered work and experience sampling research on recovery, the present study makes three key contributions to the recovery experiences literature. First, we enhance extant understanding of employee recovery and offer the first empirical test, to our knowledge, to demonstrate the presence of profiles of daily recovery experiences. Via an experience sampling study of 207 full-time employees over one work week, we used multilevel latent profile analysis (MLPA) to identify five profiles of daily recovery experiences. Further, we illustrate the extent to which profile membership varies across days. Thus, our study is the first to highlight that employees' daily recovery is characterized by the co-occurrence of recovery experiences, as opposed to a singular recovery experience.

Second, we examine the dynamic nature of recovery experience profiles in the context of 
employees' daily work experiences. Consistent with meta-analytic research (Bennett, Bakker, \& Field, 2018), we theorize that daily recovery experience profile membership is predicted by dayspecific demands (e.g., role ambiguity, time pressure) and resources (e.g., social support).

Previous research by Bennett et al. (2016) on recovery experience profiles found limited support for job demands influencing the extent to which people jointly used recovery experiences. Owing to the fact that this work may have missed important effects due to its focus on between-person, rather than within-person, differences, our study clarifies the extent to which daily job demands and resources serve as key antecedents of recovery profile membership. In so doing, we consider opposing propositions of two prominent theories drawn upon in recovery research — the EffortRecovery Model (ERM; Meijman \& Mulder, 1998) and the Job Demands-Resources model (JDR; Bakker \& Demerouti, 2007, 2017). Further, by testing both a challenge stressor (i.e., time pressure) and a hindrance stressor (i.e., role ambiguity), we explore whether different stressors exhibit disparate relationships with conjoint use of recovery experiences on a daily basis, a consideration that has received limited attention in work on employees' daily recovery processes.

Finally, given that recovery aids in recuperation (Sonnentag \& Fritz, 2007), we examine whether daily recovery experience profiles affect employee well-being during the subsequent workday, conceptualized as lower levels of emotional exhaustion, higher levels of work engagement, and improved levels of sleep quality. The focus on well-being has been dominant in recovery experience research (e.g., Bennett et al., 2016, 2018; Kinnunen, Feldt, Siltaloppi, \& Sonnentag, 2011; Sonnentag \& Fritz, 2015); our work further develops our understanding of recovery experience relationships with this criterion. However, absent from the majority of within-person recovery experience research has been a focus on how daily recovery experiences translate to workplace behaviors (Demerouti, Bakker, Geurts, \& Taris, 2009; Sonnentag et al., 
2017). Indeed, despite the fact that fluctuations in daily energy have been linked to outcomes such as citizenship behaviors (for a review, see Sonnentag, 2015), little is known about how recovery experiences affect workplace behaviors the following day, which is also true of research using a person-centered approach to employee recovery (Bennett et al., 2016; Siltaloppi et al., 2011). Thus, we explore how profiles of daily recovery experiences uniquely relate to two salient next-day workplace behaviors - coworker-focused helping and personal initiative (e.g., Sonnentag, 2003) - in an effort to understand how recovery can not only assist employees' wellbeing, but also their ability to go above and beyond their work roles.

\section{A Review of Extant Recovery Research}

The majority of recovery research draws from the ERM (Meijman \& Mulder, 1998), which contends that coping with work stressors and accomplishing work tasks requires energy and effort, ultimately leading to physiological and psychological strain. To prevent this, it is imperative that employees recover, replenish their resources, and recuperate during nonwork time (Sonnentag, 2001). Although individuals may recover through various activities, a broad stream of research has focused on the psychological experiences that underlie the recovery process versus the activities themselves (Sonnentag et al., 2017). To this end, scholars have examined four recovery experiences introduced by Sonnentag and Fritz (2007): psychological detachment, which refers to "switching off" from work mentally and physically; relaxation, which refers to experiencing low physical and/or mental activation; mastery, which involves having positive challenging experiences and learning new skills; and control, which refers to deciding how to spend nonwork time. These experiences aid employees by reducing workrelated mental activation after hours, helping employees rebuild resources lost during work (Meijman \& Mulder, 1998; Siltaloppi et al., 2011; Sonnentag \& Fritz, 2007). 
In light of increased knowledge surrounding the day-to-day fluctuations in work stressors and demands, recovery researchers have paid empirical attention to daily recovery post-work, noting its association with next day well-being (e.g., Sonnentag, 2003; Sonnentag, Binnewies, \& Mojza, 2008; Sonnentag, Mojza, Demerouti, \& Bakker, 2012). Notwithstanding the valuable insights offered by extant work on daily recovery processes, this work has limitations. First, despite Sonnentag and Fritz's (2007) call to explore how recovery experiences influence daily variations in work behaviors, empirical research examining this has been lacking (Demerouti, Bakker, Geurts, \& Taris, 2009; Sonnentag et al., 2017). Indeed, our review of the literature suggests that only three daily studies have examined behavioral criteria (e.g., Binnewies, Sonnentag, \& Mojza, 2009; Sonnentag, 2003; Volman, Bakker, \& Xanthopoulou, 2013); yet, these studies looked at subjective reports of feeling recovered, rather than the effects of specific recovery experiences (see below for further detail). Thus, although scholars have assumed that post-work recovery experiences foster desirable next-day work behaviors due to increased resources (Binnewies et al., 2009), evidence surrounding this relationship is nascent.

Second, past work has not thoroughly examined the four recovery experiences delineated by Sonnentag and Fritz (2007). Rather, some scholars (e.g., Binnewies et al., 2009; Sonnentag et al., 2012) have examined the state of feeling recovered, and others have explored daily recovery experiences as a composite (e.g., psychological detachment and relaxation; van Wijhe, Peeters, Schaufeli, \& Ouweneel, 2013), making it unclear which experiences drive recovery. This is problematic, given that Sonnentag and Fritz (2007) emphasize that recovery experiences are conceptually distinct. Further, daily studies that have examined the discrete impact of recovery experiences typically consider the effect(s) of only one or two experiences (e.g., Park, Fritz, \& Jex, 2018; Sonnentag \& Bayer, 2005; Sonnentag \& Binnewies, 2013; ten Brummelhuis \& 
Bakker, 2012; see Michel, Turgut, Hoppe, \& Sonntag [2016] and Sonnentag et al. [2008] for notable exceptions). This approach provides a limited understanding of the influence of each recovery experience above and beyond the influence of the others. In fact, in their review of the literature, Sonnentag et al. (2017) noted that studies of daily recovery experiences have largely focused on psychological detachment, overlooking the effects of the other three experiences.

Third, in focusing on certain recovery experiences in isolation, scholars have implicitly ignored the possibility that daily recovery experiences can co-occur. Work by van Wijhe et al. (2013) hints at this possibility, but their composite of psychological detachment and relaxation does not account for the possibility that employees may use varying levels of both experiences. Consistent with this idea, recent recovery research has emphasized the necessity of adopting a person-centered approach, wherein recovery experiences combine to create profiles. Siltaloppi et al. (2011) first explored this idea using a longitudinal design to identify five patterns of employees' recovery experiences over a one year period: (1) high levels of all four recovery experiences across time; (2) high, but decreasing, levels of mastery and control; (3) high levels of relaxation and mastery, with increasing levels of control; (4) stable levels of relaxation across time, but decreasing levels of psychological detachment, mastery, and control; and, (5) low levels of all four recovery experiences across time. More recently, Bennett et al. (2016) used a between-person design to identify three 'in general' profiles of recovery experiences. Consistent across two studies, three profiles emerged: (1) employees who were "leaving work behind," reporting high levels of all four experiences; (2) employees who were "recovering ponderers," with moderate levels of all recovery experiences as well as problem-solving pondering (i.e., proactively thinking about work-related problems after hours); and (3) employees who were “pondering" after work, exhibiting low levels of all four recovery experiences and, instead, 
spending their nonwork time proactively thinking about work-related issues.

These longitudinal and/or static perspectives of prior profile research is somewhat misaligned with the contemporary literature demonstrating the dynamic fluctuations that underlie recovery in light of daily demands (Bono et al., 2013; Derks et al., 2014; Hülsheger et al., 2014; Sonnentag \& Bayer, 2005). As such, an employee may have high levels of psychological detachment and relaxation one evening, but high levels of all four recovery experiences the next. Thus, in the current study, we explore whether employees' recovery processes are characterized by distinct combinations of daily recovery experiences. The identification of unique ways in which daily recovery experiences combine can yield new insights into employees' recovery, addressing several key questions that remain unanswered. For instance, which daily demands and resources help (or hinder) employees' post-work recovery experiences? To what extent do employees consistently use the same combination of recovery experiences day-to-day? Do individuals need to engage in high levels of all four experiences to reap the benefits of improved well-being and work behaviors? Alternatively, is engagement in certain recovery experiences, but not others, more critical to these outcomes? Adopting a person-centered lens of employees' daily recovery experiences allows for an examination of these intra-individual questions, and furthers our understanding of how employees' recovery processes differ on a daily basis.

\section{A Person-Centered Approach: Latent Profiles of Daily Recovery Experiences}

We adopt a person-centered approach to study the extent to which recovery experiences occur conjointly and within people daily to impact outcomes (Gabriel, Campbell, Djudjevic, Johnson, \& Rosen, 2018; Wang \& Hanges, 2011). Theoretically, the value of a person-centered approach lies in its ability to identify unique profiles of variables, uncovering distinct unobserved subpopulations within a sample. Such subpopulations can differ quantitatively and qualitatively 
(Wang \& Hanges, 2011). Quantitatively distinct profiles vary based on the absolute value, or level, of the profile indicators, or the constructs being examined (i.e., recovery experiences; Gabriel, Daniels, Diefendorff, \& Greguras, 2015; Marsh, Lüdtke, Trautwein, \& Morin, 2009). In the context of daily recovery experiences, a quantitatively distinct profile could be characterized by evenings in which employees feel high (low) levels of psychological detachment, relaxation, mastery, and control. Conversely, qualitatively distinct profiles vary based on the relative standing of each profile indicator (i.e., varying in 'shape;' Marsh et al., 2009). A qualitative profile in the current study could reflect evenings in which employees experienced high levels of psychological detachment and relaxation, but low levels of mastery and control, or evenings characterized by high levels of psychological detachment, relaxation, and control, but low mastery. Such qualitative differences are rarely captured through variable-centered (i.e., regression-based) approaches (Wang \& Hanges, 2011). Thus, adopting a person-centered approach can render a nuanced - and once-overlooked - theoretical understanding of how recovery experiences may combine daily (Gabriel et al., 2018; Wang \& Hanges, 2011).

The inductive nature of LPA precludes formal predictions regarding both the number of profiles that will emerge, as well as the level and shape of profiles (Gabriel et al., 2018; Morin et al., 2011). Nonetheless, in the current context, certain profiles are theoretically plausible. For instance, there are likely evenings in which employees are able to completely unplug from work, reporting high levels of all four recovery experiences. Alternatively, there may be days wherein employees remain preoccupied with work, preventing them from "switching off" (e.g., Lanaj, Johnson, \& Barnes, 2014) and resulting in low levels of all four recovery experiences. Further still, evenings may be characterized by specific pairings of recovery experiences, such as high levels of psychological detachment and relaxation (but not mastery and control) or 
feelings of detachment, relaxation, and control (but low mastery). Thus, to preserve the inductive nature intended for LPA (Wang \& Hanges, 2011), and given that no work to date has investigated the presence of within-person profiles of daily recovery experiences, we pose the following initial research question for consideration:

Research Question 1: Do profiles of daily recovery experiences-psychological detachment, relaxation, mastery, and control—exist for employees?

\section{Is Membership in Profiles of Daily Recovery Experiences Stable or Dynamic?}

Assuming that profiles of daily recovery experiences exist, a natural — and relatedquestion is to what extent is membership in such daily profiles stable or dynamic over time (i.e., over one work week)? The stability of profile membership can be conceptualized in two ways. First, stability can refer to whether employees report the same combination of recovery experiences daily (i.e., membership in the same profile across all days), or if employees report different combinations of recovery experiences, belonging to different profiles across workdays in a week. Second, stability can refer to whether employees stay in the same profile day after day, or if they belong to a different profile from one day to the next. Thus, there may be day-today fluctuations in profile membership, in that membership is a dynamic phenomenon.

According to the ERM, recovery processes are necessary to alleviate strain reactions from expending effort in coping with work stressors (Meijman \& Mulder, 1998). Because employees experience varying stressors each day, both the need to recover and the specific recovery experiences that employees report may similarly fluctuate daily (Derks et al., 2014; Sonnentag \& Bayer, 2005; Sonnentag \& Zijlstra, 2006; Volmer et al., 2012). For example, there may be certain days that are not characterized by any recovery experience, other days during which employees only detach and relax, and yet other days when employees are able to feel fully 
disconnected from work via all four experiences. Conversely, employees may consistently rely on the same combination each day; as an example, employees may consistently experience relaxation and mastery post-work day after day. This suggests that-similar to other intraindividual constructs - there are within- and between-person components to daily recovery experience profile membership. Although prior work on general recovery experiences has implicitly assumed the latter (i.e., employees are stable in their profile membership; Bennett et al., 2016; Siltaloppi et al., 2011), it is yet unclear whether employees change recovery profile membership day-to-day. Thus, we aim to not only explore daily profiles of recovery experiences, but also the stability of such profiles by addressing the following research question:

Research Question 2: Is membership in daily recovery experiences profiles stable?

\section{Antecedents of Profiles of Daily Recovery Experiences}

Aside from establishing the existence and stability of daily recovery profiles, we also sought to discern the antecedents that differentiate profile membership. Recently, scholarship on antecedents of recovery experiences has begun to expand beyond ERM to also consider the JD-R perspective, which offers theoretical assertions that are divergent from prior assumptions. More specifically, according to the ERM, recovery is crucial to employee well-being after exposure to work stressors (Meijman \& Mulder, 1998); thus, although not explicitly posited, the ERM view suggests that increased recovery experiences should follow workdays characterized by high job demands, given that employees can replenish lost resources when they return home and are (theoretically) not working (e.g., Binnewies, Sonnentag, \& Mojza, 2010; Demerouti et al., 2009; Mojza, Lorenz, Sonnentag, \& Binnewies, 2010). Consequently, the implicit assumption of the ERM is that days with high job demands should facilitate employee recovery post-work as employees need their resources replenished (Meijman \& Mulder, 1998), increasing the 
likelihood that employees conjointly report multiple recovery experiences after working hours. Yet, empirical evidence supporting this proposition is equivocal: although prior work has found that daily job demands are positively associated with need for recovery (Sonnentag \& Zijlstra, 2006), research has also reported that job demands are negatively related to intra-individual recovery experiences (Mojza et al., 2010; Sonnentag \& Bayer, 2005; Volmer et al., 2012).

Although unsupportive of central tenets from the ERM, the aforementioned findings do align with ideas posed by the JD-R model (Bakker \& Demerouti, 2007), which classifies psychosocial work characteristics into job demands and job resources. Job demands (e.g., time pressure, role ambiguity) are aspects of work that require psychological or physiological effort, whereas job resources (e.g., social support) are restorative to employees' well-being at work (Bakker \& Demerouti, 2007, 2017). While original JD-R theorizing did not consider recovery per se, research has recently begun to draw on the JD-R model to hypothesize that job demands impair employees' recovery processes post-work as they remain preoccupied with job demands (Bennett et al., 2018; Demerouti et al., 2009; Kinnunen et al., 2011). Thus, days characterized by high job demands should decrease recovery experiences after hours.

In considering the effects of daily job demands on profiles of daily recovery experiences, we build from the ERM and JD-R model, as well as job demands research that distinguishes types of stressors (LePine, Podsakoff \& LePine, 2005; Podsakoff, LePine, \& LePine, 2007; Rodell \& Judge, 2009), to examine the extent to which time pressure and role ambiguity predict profile membership. Prior research has established that employees' experiences of time pressure and role ambiguity vary daily, yielding implications for employee well-being and performance (e.g., Kühnel, Sonnentag, \& Bledow, 2012; Ohly \& Fritz, 2010; Yang \& Diefendorff, 2009). Further, studies adopting both variable-centered (e.g., Kinnunen et al., 2011) and, to a limited 
extent, person-centered approaches (e.g., Bennett et al., 2016) have examined job demands as antecedents of recovery experiences. In fact, in their seminal work, Sonnentag and Fritz (2007) considered time pressure and role ambiguity as central, theoretically-relevant correlates of recovery experiences. Thus, we sought to build directly on this research by exploring daily time pressure and role ambiguity as antecedents of daily recovery experience profile membership.

Time pressure represents a challenge stressor characterized as growth-promoting (Rodell \& Judge, 2009; Tadić Vujčić, Oerlemans, \& Bakker, 2017). Critically, the high activation that arises from challenge stressors can make detachment and relaxation difficult as employees continue to think about work issues (Bennett et al., 2016, 2018; Kinnunen et al., 2011; Sonnentag et al., 2017). Continuously thinking about work could also impede the extent to which employees perceive control during nonwork time. Indeed, increased time pressure may prompt employees to bring work home, in that they continue to think about and/or make progress on work tasks after hours. Thus, although time pressure may be motivating during the workday, it is likely a source of strain at home (LePine, LePine, \& Saul, 2007), inhibiting post-work recovery. Alternatively, such growth-promoting experiences at work may spill into nonwork positively, driving mastery experiences such as learning and developing a new skill (Michel et al., 2016). To this end, workdays with higher time pressure may increase the likelihood that employees experience higher mastery, but lower conjoint levels of psychological detachment, relaxation, and control.

In contrast, role ambiguity is characterized as a hindrance stressor, reflecting a demand that interferes with employees' abilities to achieve valued outcomes (Rodell \& Judge, 2009) and is considered growth-thwarting (Tuckey, Searle, Boyd, Winefield, \& Winefield, 2015). Similar to time pressure, role ambiguity likely increases the extent to which employees think about work at home (Sonnentag \& Fritz, 2007; Sonnentag \& Kruel, 2006), averting detachment, relaxation, 
and feelings of control (Bennett et al., 2016; Michel et al., 2016). However, in contrast to time pressure, role ambiguity likely impedes employees' experiences of mastery post-work, as hindrance stressors require self-regulation (Sonnentag \& Jelden, 2009) and are demotivating (LePine et al., 2005). Thus, it is plausible that workdays with higher role ambiguity increase employees' preoccupation with work, resulting in lower levels of all recovery experiences.

In addition to the impairing effects of job demands, the JD-R model contends that job resources - such as social support - can protect and enhance employee well-being (Bakker, Hakanen, Demerouti, \& Xanthopoulou, 2007; Crawford, LePine, \& Rich, 2010), promoting recovery post-work due to an increased sense of calmness, facilitating relaxation, as well as greater internal resources (e.g., energy) that can be devoted to gaining mastery experiences and control over nonwork time (e.g., learning a new skill; Kinnunen et al., 2011; Sonnentag \& Fritz, 2007). However, the benefits associated with job resources can reduce psychological detachment as employees ponder the positive aspects of their jobs (i.e., thinking of how to support others), remaining actively tied to work issues (Bennett et al., 2018; Kinnunen et al., 2011; Sonnentag \& Fritz, 2007). Prior profile analytic work has not yet considered how resources from others aid recovery (e.g., Bennett et al., 2016), despite empirical support for the impact of social support on recovery experiences (Kinnunen \& Feldt, 2013; Kinnunen et al., 2011; Sonnentag \& Fritz, 2007). In sum, we explore the extent to which daily job demands (role ambiguity and time pressure) and job resources (social support) help differentiate daily recovery experience profile membership.

Research Question 3: Do daily job role ambiguity, time pressure, and social support predict membership in profiles of daily recovery experiences?

\section{Outcomes of Profiles of Daily Recovery Experiences}

There is little doubt surrounding the replenishing benefits when employees recover from 
work (Bennett et al., 2018; Sonnentag et al., 2017). Specifically, recovery experiences can aid replenishment by reversing load reactions via lower work-related activation and cessation of job demands, or by building and/or replacing threatened or lost resources (Sonnentag \& Fritz, 2007). Reversing load reactions typically occurs through psychological detachment and relaxation, while building resources occurs through mastery and control (Bennett et al., 2018). However, it is yet unclear whether certain combinations of daily recovery experiences are more or less beneficial. Extending Bennett et al. (2016), we examine factors associated with well-being (e.g., sleep quality, emotional exhaustion, and work engagement) and also behavioral criteria (e.g., helping and personal initiative) in relation to daily recovery experience profile membership.

As recovery experiences aid in restoring resources (Sonnentag \& Fritz, 2007), recovering in the evenings through conjoint experiences should be the most beneficial in terms of increased next-day well-being and greater enacted work behaviors. Yet, when considering specific profiles of daily recovery experiences, certain pairings may be more or less critical to behavioral versus well-being outcomes (and vice versa). For instance, helping and personal initiative may be more likely following evenings in which employees report recovering through mastery and control (but not psychological detachment and relaxation), as these experiences build new resources (Bennett et al., 2018; Siltaloppi, Kinnunen, \& Feldt, 2009) that can be expended toward tasks that require employees to go above and beyond their formal role descriptions. In contrast, simply reversing load reactions through psychological detachment and relaxation may be sufficient to benefit well-being (Siltaloppi et al., 2009). In light of these possibilities, we pose the following:

Research Question 4: Do profiles of daily recovery experiences differentially relate to next-day well-being (sleep quality, emotional exhaustion, and work engagement) and workplace behaviors (helping and personal initiative)? 


\section{Method}

\section{Participants and Procedure}

In order to obtain a diverse sample of full-time employees, we recruited participants through personal and professional networks. Specifically, we posted an advertisement detailing the nature of the study on professional listservs and social media platforms (e.g., LinkedIn) ${ }^{1}$; interested participants were also encouraged to send details and/or advertise the study to other full-time employees who may be interested in participating. The advertisement contained a link to the opt-in survey, which included eligibility criteria and demographics. To be eligible, participants had to be full-time employees $(32+$ hours per week) in the U.S. working at least five days a week during fairly regular work hours (i.e., arriving by 9:30 a.m. and leaving no earlier than 3:30 p.m.). Individuals were also required to work in standard working arrangements (e.g., working outside of the home for at least 25 hours per week). Participants were told that they would be surveyed twice a day for five consecutive working days (i.e., one work week), and could earn up to $\$ 45$. In total, 232 employees opted in and consented to participate in the study.

Two weeks later, participants began receiving two surveys a day-one in the morning before their workday began (completed at approximately 8:16 AM on average) and one in the afternoon at the end of the workday (completed at approximately 4:50 PM on average). The morning survey assessed individuals' recovery experiences from the previous night, as well as sleep quality and emotional exhaustion. The afternoon survey again assessed emotional exhaustion, as well as work engagement, helping, and personal initiative; this survey also

\footnotetext{
${ }^{1}$ Although there are concerns surrounding the use of such online recruiting methods (e.g., Marcus, Weigelt, Hergert, Gurt, \& Gelléri, 2017), we collected several pieces of information (e.g., first and last name, complete mailing address) in keeping with the requirements of the university at which the institutional review board approval was obtained. Additionally, we ensured that payment checks were deposited in each individual's personal bank account within 60 days of receipt. Thus, there were multiple ways by which we verified each participant.
} 
captured role ambiguity, time pressure, and social support, all of which were modeled as

antecedents via lagged analyses (see Analytic Approach). As "larger sample sizes increase the ability to detect more complex profile solutions" (Gabriel et al., 2018, p. 21), it was necessary to maximize the Level 1 sample size of our primary construct of interest-recovery experiences. Our final dataset comprised responses from 207 participants (out of 232; 89.2\% retained) who provided assessments of their recovery experiences for at least three workdays (e.g., Rosen, Koopman, Gabriel, \& Johnson, 2016). At Level 1, participants generated 967 morning responses (4.7 surveys per person) and 891 afternoon surveys (4.3 surveys per person) out of a possible 1,035 (93.4\% and $86.1 \%$ response rate, respectively). Our sample was largely female (69.1\%) and white $(73.9 \%)$ with an average age of 32.8 years (range $=21-64)$. Employees came from 28 diverse industries, of which education (19.8\%), healthcare (17.9\%), finance (9.7\%), and manufacturing (5.3\%) were most common, and held 158 unique job titles, ranging from accountant to speech pathologist. The majority of employees (57.5\%) did not hold a supervisory position. On average, employees worked $43.0(S D=5.9)$ hours per week, and had worked 4.0 years in their current job $(S D=4.3)$ and 4.9 years in their current organization $(S D=5.2)$.

\section{Daily Survey Measures}

Items were on a 5 -point scale $(1=$ strongly disagree $; 5=$ strongly agree $)$ unless noted ${ }^{2}$. Recovery Experiences (Morning). We adapted Sonnentag and Fritz's (2007) Recovery

\footnotetext{
${ }^{2}$ As the data reported were part of a larger data collection effort, we note that half of the participants in our study were randomly assigned to complete our daily antecedents — role ambiguity, time pressure, and social support—on a 9-point scale $(1=$ strongly disagree; $9=$ strongly agree $)$. To examine the comparable validity of the two responses formats, we conducted two multilevel confirmatory factor analyses - one on the dataset wherein participants rated the antecedents on a 5-point scale $\left(\chi_{(1311)}^{2}=1906.86, \mathrm{CFI}=.92, \mathrm{RMSEA}=.03, \mathrm{SRMR}_{\text {within }}=.05\right)$ and another on the dataset with antecedents rated on the 9-point scale $\left(\chi^{2}(1311)=1997.07, \mathrm{CFI}=.91, \mathrm{RMSEA}=.03, \mathrm{SRMR}_{\text {within }}=.05\right)$. The fit indices were comparable, suggesting that the items similarly represent the underlying latent constructs, regardless of response format. Based on these analyses, we considered participants as part of a large, aggregate sample. As such, we converted scores for participants who rated the antecedents on a 9-point scale to a 5-point scale, preventing discrepancies across our sample. All remaining measures, for all participants, were rated on a 5-point scale. As a note, this is the first manuscript based on the data collected as part of the larger data collection effort.
} 
Experiences Questionnaire to assess daily recovery experiences on a 5-point scale $(1=$ not at all; $5=$ very much); each experience was measured through four items and participants reflected on the previous night after working hours. Example items include "Last night, I did not think about work at all" (psychological detachment; $\alpha=.86$ ); "Last night, I kicked back and relaxed" (relaxation; $\alpha=.93$ ); "Last night, I did things that challenged me" (mastery, $\alpha=.84$ ); and, "Last night, I decided my own schedule" (control; $\alpha=.90)$.

Sleep Quality (Morning). We measured sleep quality with a single item from the Pittsburgh Sleep Quality Index (Buysse, Reynolds, Monk, Berman, \& Kupfer, 1989) that asked participants how they would evaluate their previous night's sleep $(1=$ very poor $5=$ very good $)$.

Emotional Exhaustion (Morning and Afternoon). We used three items adapted from Wharton $\left(1993 ; \alpha_{\text {morning }}=.85 ; \alpha_{\text {afternoon }}=.85\right)$. Participants rated how they were currently feeling on a 5-point scale $(1=$ not at all; $5=$ extremely $)$. An item is "I feel emotionally drained."

Role Ambiguity (Afternoon). To capture daily role ambiguity, we used Yang and Diefendorff's (2009) four-item scale ( $\alpha=.82$ ). An item is: "Today, clear, planned goals and objectives were provided for my job." Items were reverse-coded to reflect higher role ambiguity.

Time Pressure (Afternoon). Daily time pressure was assessed with three items from Ohly and Fritz (2010; $\alpha=.89)$. A sample item is: "Today, I was under time pressure."

Social Support (Afternoon). We measured perceptions of workplace social support using three items adapted from Zimet, Dahlem, Zimet, and Farley (1988; $\alpha=.74)$. An example item is: "Today, I received emotional help and support that I needed from someone at work."

Engagement (Afternoon). Following prior research (e.g., Bennett et al., 2016; Schaufeli, Bakker, \& Salanova, 2006), we measured individuals' engagement at work with nine items from the Utrecht Work Engagement Scale ( $\alpha=.83$ ); items were summed to form a composite score 
across the three dimensions of absorption, dedication, and vigor. Items were adapted to capture daily levels of engagement; for example, "Today, I was immersed in my work."

Helping Behaviors (Afternoon). We used six items from Lee and Allen $(2002 ; \alpha=.74)$ to capture daily engagement in helping behaviors. Participants rated the frequency with which they engaged in each behavior that day at work on a 5 -point scale $(1=$ never $;=$ very often $)$. A sample item is: "Today, I willingly gave time to help others who had work-related problems."

Personal Initiative (Afternoon). We assessed personal initiative using Frese, Fay, Hilburger, Leng, and Tag's (1997; $\alpha=.84)$ seven-item scale. Items were modified to reflect daily proactive behavior, rated on a 5 -point scale $(1=$ never; $5=$ very often $)$. An example item is: "I searched for a solution immediately whenever something went wrong today."

\section{Analytic Approach}

Given the non-independence of the data (i.e., days nested within people), we conducted MLPA (e.g., Klotz, Bolino, Song, \& Stornelli, 2018; Morin et al., 2017). As a first step, we ran null models using Mplus Version 7.4 (Muthén \& Muthén, 1998-2015), decomposing betweenand within-person variance in each variable. As shown in Table 1, 31.5\% to $73.3 \%$ of the variance in our constructs was within-person, supporting our use of MLPA. We next ran a multilevel confirmatory factor analysis (CFA), modeling our four recovery experiences as distinct factors plus our antecedents (role ambiguity, time pressure, and social support) and outcomes (emotional exhaustion in the morning and afternoon, engagement, helping behavior, and personal initiative) at Level 1. Following Scott, Colquitt, Paddock, and Judge (2010), items were within-person centered. Results indicated good fit $\left(\chi^{2}{ }_{(1311)}=2160.40, \mathrm{CFI}=.94 ; \mathrm{RMSEA}=\right.$ $\left..03, \mathrm{SRMR}_{\text {within }}=.04\right)^{3}$, supporting our factor structure and the validity of our measures.

\footnotetext{
${ }^{3}$ Consistent with best practices, we compared these results to three alternative models. First, we examined a model wherein we collapsed the four recovery experiences into a single latent factor; this model exhibited worse fit $\left(\chi^{2}(1341)\right.$
} 
In line with prior recommendations, we used raw scores in our MLPA analyses given that "group-mean centering... should not be used in MLPA because it can substantially change model interpretation” (Mäkikangas et al., 2018, p. 4). In modeling our profiles of daily recovery experiences, we allowed the means of the profile indicators (i.e., recovery experiences) to be freely estimated across profiles, but not the variances. This is the appropriate analytic decision if the model does not converge when the variances are freely estimated (e.g., Bauer \& Curran, 2003; Gabriel et al., 2018; Morin et al., 2016), as was the case with our within-person data.

MLPA is an inductive approach, and as such, the number of profiles is not known $a$ priori. Thus, we specified a two-profile solution and increased the number of latent profiles until there was no further improvement in model fit (Nylund, Asparouhov, \& Muthén, 2007). We report seven fit statistics: Log Likelihood (LL), Akaike Information Criterion (AIC), Bayesian Information Criterion (BIC; recommended by Nylund et al., 2007), sample-size-adjusted BIC (SSA-BIC), consistent AIC (CAIC), Lo-Mendell-Rubin likelihood ratio test (LMR; Lo, Mendell, \& Rubin, 2001), and Entropy. Although there are no formal cut-off scores to determine fit, based upon recent simulations, the best-fitting solution should have lower BIC, SSA-BIC, and CAIC values compared to other solutions (e.g., Diallo, Morin, \& Lu, 2016, 2017; Peugh \& Fan, 2013, 2015). To aid in interpretation, and establish the gains in model fit for each additional profile specified, we calculated an elbow plot of the BIC and C-AIC values (Howard, Gagné, Morin, \& Van den Broeck, 2016), examining the point at which the slope of the plot flattens (Morin \& Marsh, 2015). We also considered prior recommendations of solutions having a significant LMR

$\left.=5109.63, \mathrm{CFI}=.73, \mathrm{RMSEA}=.05, \mathrm{SRMR}_{\text {within }}=.07\right)$. Second, we tested a model wherein we collapsed role ambiguity and time pressure into a single latent factor (i.e., job demands); this model also demonstrated worse fit $\left(\chi_{(1332)}^{2}=3932.47, \mathrm{CFI}=.81, \mathrm{RMSEA}=.05, \mathrm{SRMR}_{\text {within }}=.06\right)$. Finally, we examined a model wherein we collapsed helping and personal initiative (i.e., discretionary behaviors) into a single latent factor; this model also exhibited worse fit $\left(\chi_{(1332)}^{2}=3604.77, \mathrm{CFI}=.84, \mathrm{RMSEA}=.04, \mathrm{SRMR}_{\text {within }}=.06\right)$. Therefore, the hypothesized model had the best fit and was retained for all subsequent analyses. 
statistic $(p<.05)$ and an Entropy value larger than other solutions (Jung \& Wickarama, 2008), indicating greater classification accuracy. Finally, we examined whether there were theoretically redundant profiles in order to select a theoretically parsimonious solution (Howard et al., 2016).

We followed the automatic three step-procedure for MLPA (Asparouhov \& Muthén, 2014). The first step involved profile enumeration and selecting the best-fitting profile solution. In the second step, the most-likely class membership was obtained based on the posterior distribution from the first step. The last step examined antecedents and outcomes in relation to the profile solution; importantly, the most likely class membership and classification error rate are taken into consideration when running analyses (Wang \& Hanges, 2011). Consistent with past research (e.g., Hipp \& Bauer, 2006; Morin, Meyer, Creusier, \& Biétry, 2016), each model used 5000 sets of starting values, with the best 200 sets retained for final stage optimization.

To model antecedents and outcomes - which were conducted separately (Lanza, Tan, \& Bray, 2013) — we used the R3STEP and BCH commands, respectively (Asparouhov \& Muthén, 2014). The R3STEP utilizes multinomial logistic regression to assess whether an increase in an antecedent increases the likelihood that an individual belongs to one profile compared to another (Bennett et al., 2016; Gabriel et al., 2015). In order to increase interpretability of the data, we calculated odds ratios (ORs) for each profile comparison using the absolute value of the coefficient generated from the R3STEP analysis, capturing "the change in likelihood of membership in a target profile versus a comparison profile associated for each unit increase in the predictor" (Morin et al., 2016, p. 246). ORs greater than one indicate the number of times a person is more likely to belong to the target profile versus the comparison profile. We used the $\mathrm{BCH}$ command to test relationships with our outcome variables (Bolck, Croon, \& Hagenaars, 2004; see Asparouhov \& Muthén, 2015; Bakk \& Vermunt, 2016). The BCH analysis indicates 
whether one profile is significantly different from other profiles on each outcome; this procedure avoids shifts in profile membership in the final stage of the three-step approach and uses a weighted multiple group analysis (Asparouhov \& Muthén, 2015). Missing data on the antecedent constructs (i.e., job demands and resources) are handled using listwise deletion in R3STEP analyses; on the other hand, missing data on the outcome constructs (i.e., well-being and work behaviors) are handled using full information maximum likelihood estimation in BCH analyses.

To empirically test how daily job demands predict daily recovery profile membership, we modeled antecedents (i.e., role ambiguity, time pressure, social support) during the afternoon of the prior workday $(t-1)$, with profiles of daily recovery experiences modeled from reports captured the morning of day $t$ (reflecting on participants' experiences the prior evening). In an effort to explore how daily recovery profile membership impacts next-day well-being and work behaviors, sleep quality and emotional exhaustion were captured in the morning of day $t$ (i.e., at the same time as recovery experiences), with work engagement, helping, and personal initiative modeled in the afternoon of day $t$; emotional exhaustion was also reassessed in the afternoon of day $t$. Conducting lagged analyses allowed us to perform more rigorous tests of empirical relationships (Podsakoff, MacKenzie, Lee, \& Podsakoff, 2003).

\section{Results}

Descriptive statistics and within-person correlations are in Table 2; results of our profile enumeration are in Table 3. As indicated in Table 3, the five-profile solution exhibited better fit (i.e., lower BIC, SSA-BIC, and CAIC, a significant LMR statistic [ $p<.05]$, higher Entropy) compared to the two-, three-, and four-profile solutions. Although the six-profile solution had slightly lower BIC, SSA-BIC, and CAIC statistics and higher Entropy, we retained the fiveprofile solution given the additional profile was theoretically redundant (i.e., closely mirrored the 
non-mastery recovering profile; see below). Additionally, the Elbow plot (see Figure 1) indicated that the slopes taper around the five-profile structure, lending further support for our decision.

\section{Research Question 1: Profiles of Daily Recovery Experiences}

Table 4 displays the descriptive information associated with each recovery profile and Figure 2 illustrates the quantitatively and qualitatively different profiles ${ }^{4}$. The profile with the largest membership (28.6\%) reflected evenings in which employees experienced moderate control $(M=3.50)$ predominantly and, to a slightly lesser extent, psychological detachment $(M=$ 3.01) and relaxation $(M=2.95)$, but very low mastery $(M=1.69)$; we labeled this profile controlled non-mastery recovering. The profile with the second largest membership (22.6\%) represented evenings characterized by non-mastery recovering; these evenings were typified by higher levels of psychological detachment $(M=4.08)$, relaxation $(M=4.45)$, and control $(M=$ 4.32) compared to the controlled non-mastery recovering profile, but similarly low levels of mastery $(M=1.73)$. Our third largest profile $(21.1 \%)$ reflected evenings with low psychological detachment $(M=2.31)$, relaxation $(M=1.85)$, mastery $(M=1.67)$, and control $(M=2.38)$.

Given the low levels of all four recovery experiences, we referred to this profile as plugged in. The fourth profile (19.7\%), labeled moderately unplugged, represented higher mean levels of all recovery experiences (psychological detachment $M=3.31$; relaxation $M=3.68$; mastery $M=$ 3.29; control $M=3.87$ ) compared with our plugged in profile. Finally, the profile with the smallest membership (8.0\%) was typified by relatively high levels of psychological detachment $(M=4.43)$, relaxation $(M=4.71)$, mastery $(M=4.17)$, and control $(M=4.62)$. We labeled this the unplugged profile given the heightened use of all four recovery experiences. Thus, with

\footnotetext{
${ }^{4}$ Based on a suggestion by an anonymous reviewer, we also examined the five profiles of daily recovery experiences using standardized item scores; the plot of the profile solutions were consistent with that using raw scores of daily recovery experiences (i.e., Figure 2) and is available from the first author upon request.
} 
respect to Research Question 1, daily recovery experience profiles do exist, representing two qualitatively distinct (controlled non-mastery recovering, non-mastery recovering) and three quantitatively distinct profiles (plugged in, moderately unplugged, unplugged $)^{5}$.

\section{Research Question 2: The Dynamic Nature of Daily Profile Membership}

To gain a better understanding of the stability of membership, we determined the profile that each employee was most likely to be a member of each day of our study and then calculated both the number and different types of profiles to which each individual belonged. This allowed us to explore whether individuals belonged to the same recovery profile across the week of the study or whether individuals varied in membership across days. Table 5 reports the percentage of participants that belonged to one, two, three, or four daily recovery profiles, and the specific combinations of these profiles. Half of our sample (50.7\%) belonged to two different profiles across the five days of our study; $35.8 \%$ employees belonged to three different profiles; and $3.9 \%$ belonged to four different profiles. In sum, over $90 \%$ of all employees belonged to more than one recovery profile during the week of our study. These results indicate that it is the norm — rather than the exception—-for employees to belong to different recovery profiles across days, providing preliminary evidence that daily profile membership is dynamic. Indeed, less than $10 \%$ of the sample $(n=18)$ belonged to the same profile during the course of the entire week ${ }^{6}$.

It is also possible to explore the dynamic nature of recovery profile membership as a dayto-day phenomenon. Whereas the results in Table 5 illustrate the stability of profile membership across the entire week, Table 6 shows day-to-day variation in profile membership. Specifically,

\footnotetext{
${ }^{5}$ We re-ran our MLPA using data reflecting complete responses across both the morning and afternoon surveys for at least three days (Level $2 n=207$; Level $1 n=891$ ). Analyses revealed that the five-profile structure exhibited best fit and that the profile structure replicated (see Figure 2). Results are available from the first author upon request.

6 As our final dataset was comprised of participants who provided at least three morning surveys, these values are contingent on the number of day-level observations (i.e., day-level profiles) obtained per person that were aggregated across the five workdays of our study.
} 
for employees who belonged to a specific profile on day $t$, we determined the proportion of employees who belonged to the same, or a different profile, on day $t+1$. Thus, for each two consecutive days we obtained data from participants, we calculated: (a) the percentage of all employees who belonged to each pair of daily recovery profiles (e.g., Day 1 plugged in $\rightarrow$ Day 2 plugged in: $5.7 \%$ ), and (b) the percentage of employees in the specific pair of daily recovery profiles, out of those employees who belonged to the target profile on day $t$ (e.g., Day 1 plugged in $\rightarrow$ Day 2 plugged in: $35.7 \%$ ). Using this information, for each daily recovery experiences profile, we discerned the proportion of employees who stayed in the same profile from one day to the next, thereby exploring the stability of profile membership. As indicated in the final column of Table 6, stability in membership seems to be relatively consistent across profile type, with one exception. While the plugged in (43.8\%), controlled non-mastery recovering (45.7\%), moderately unplugged (43.4\%), and non-mastery recovering (47.0\%) profiles exhibited similar levels of stability, fewer employees $(36.0 \%)$ in the unplugged profile remained in this profile the subsequent day. Thus, these findings indicate that, on average, more than half of the employees in any given recovery profile do not remain in the same profile on the next day ${ }^{7}$.

Importantly, the means reported in Table 6 may mask differences in the variability in stability in profile membership. Although the average stability of profile membership was very similar for four profiles, there were differences in the variability around these means across profiles. For example, although $50.0 \%$ of participants in the moderately unplugged profile at Day 2 remained members of this profile on Day 3, only $30.0 \%$ of employees in this profile on Day 1 stayed members on Day 2 (the $S D$ for stability was $9.2 \%$ across the four day-to-day

\footnotetext{
${ }^{7}$ There were two cases in which more than a half of employees in a given daily recovery experience profile stayed in the same profile from one day to the next during the course of our one-week study: Day 3 controlled non-mastery recovering $\rightarrow$ Day 4 controlled non-mastery recovering (51.1\%) and Day 3 non-mastery recovering $\rightarrow$ Day 4 nonmastery recovering $(53.9 \%)$.
} 
comparisons). In contrast, the controlled non-mastery recovering profile exhibited less variation in profile membership stability across days. Specifically, $42.4 \%$ of individuals in this profile on Day 2 remained members on Day 3, and $51.1 \%$ of participants in this profile on Day 3 stayed members on Day 4 (the $S D$ for stability was only $4.0 \%$ across the four day-to-day comparisons). Although the unplugged profile had the lowest average levels of stability, it had the highest level of variability around this average. More specifically, the day-to-day stability percentages ranged from $21.4 \%$ (Day $3 \rightarrow$ Day 4 ) to $44.4 \%$ (Day $1 \rightarrow$ Day 2 ), and the $S D$ across days was $10.3 \%$.

Thus, with respect to Research Question 2, there is clear evidence that membership in profiles of daily recovery experiences is dynamic within-week and day-to-day. Our findings indicate that most employees belong to multiple profiles of recovery experiences during one week. Further, it is evident that the majority of employees who are members of a profile on a given day $(t)$ are not members of the same profile on the subsequent day $(t+1)$. Combined, these results highlight the substantial day-to-day fluctuations in employees' profile membership, providing greater support for the examination of recovery experience profiles at the withinperson level of analysis. These findings also raise the question of whether, and to what extent, daily demands and resources predict profile membership from one day to the next.

\section{Research Question 3: Antecedents of Profiles of Daily Recovery Experiences}

Regarding antecedents of daily recovery profiles, our results suggest that job demands (i.e., role ambiguity, time pressure) distinguish profile membership, but job resources (social support) do not (see Table 7). We found that workdays characterized by higher role ambiguity made individuals more than one and a half times more likely to belong to the controlled nonmastery recovering profile compared to the non-mastery recovering profile $(O R=1.62 ; p<.05)$. Further, employees were about two-and-a-half to four times more likely to belong to the plugged 
in $(O R=3.78 ; p<.01)$, controlled non-mastery recovering $(O R=3.94 ; p<.01)$, moderately unplugged $(O R=2.77 ; p<.05)$, or non-mastery recovering $(O R=2.44 ; p<.05)$ profiles compared to the unplugged profile on days in which they experienced higher role ambiguity. As such, role ambiguity seems to prevent employees from disconnecting post-work, limiting their ability to recover. Similarly, time pressure made employees up to twice as likely to belong to the plugged in $(O R=2.01 ; p<.01)$, controlled non-mastery recovering $(O R=1.55 ; p<.01)$, or moderately unplugged $(O R=1.79 ; p<.01)$ profiles compared to the non-mastery recovering profile. Additionally, days characterized by higher levels of time pressure decreased the likelihood that employees belonged to the unplugged profile compared to the plugged in (OR= $1.72 ; p<.05)$ profile. In sum, experiencing role ambiguity and time pressure during the workday continues to plague employees at home, inhibiting membership in profiles characterized by engagement in high levels of several recovery experiences in tandem (e.g., our unplugged or non-mastery recovering profiles). Interestingly, daily social support did not differentiate profile membership in any way, suggesting that this job resource does not play a role in explaining why people engage in combinations of recovery experiences daily. Thus, it appears that daily job demands played a larger role in delineating profile membership compared to daily resources.

\section{Research Question 4: Outcomes of Profiles of Daily Recovery Experiences}

Finally, we examined whether our profiles exhibited differential relationships with wellbeing and work behaviors; these analyses are presented in Table 8 . With respect to well-being in the morning (i.e., sleep quality and emotional exhaustion), employees experienced better benefits when they belonged to either the unplugged or non-mastery recovering profiles. For sleep quality, employees in the non-mastery recovering $(M=3.77)$ and unplugged profiles $(M=3.66$; differences between these means were non-significant $[p>.05])$ had significantly higher $(p<$ 
$.05)$ sleep quality compared to the moderately unplugged $(M=3.32)$, controlled non-mastery recovering $(M=3.14)$, and plugged in $(M=2.81)$ profiles; the unplugged and moderately unplugged profiles were not significantly different from each other $(p>.05)$, nor were the moderately unplugged and controlled non-mastery recovering profiles $(p>.05)$. Emotional exhaustion in the morning exhibited a similar pattern: on days when employees belonged to the unplugged $(M=1.57)$ and non-mastery recovering $(M=1.71$; difference between the means was non-significant $[p>.05]$ ) profiles, they reported significantly lower (all comparisons $p<.05$ ) emotional exhaustion compared to the controlled non-mastery recovering $(M=2.17)$, and plugged in $(M=2.69)$ profiles. Further, the moderately unplugged $(M=1.97)$ profile was not significantly different from the controlled non-mastery recovering, non-mastery recovering, or unplugged profiles $(p>.05)$; all other profile comparisons were significant $(p<.05)$. The lack of significant differences between the moderately unplugged or non-mastery recovering and the unplugged profiles suggests that employees need not have high levels of all four recovery experiences for them to begin their workdays with improved well-being.

However, the lack of high levels of mastery paired with psychological detachment, relaxation, and control seems to impair well-being as the workday progresses. Employees who unplugged the night before exhibited the lowest emotional exhaustion in the afternoon $(M=$ 1.52), whereas employees who were plugged in exhibited the highest emotional exhaustion $(M=$ 2.74), compared to the non-mastery recovering $(M=1.93)$, controlled non-mastery recovering $(M=2.23)$, and moderately unplugged $(M=2.22)$ profiles (comparisons significant at $p<.05)$. Comparisons between the non-mastery recovering, moderately unplugged, and controlled nonmastery recovering profiles were not different $(p>.05)$. Similarly, work engagement was highest among employees in the unplugged and moderately unplugged profiles $(M=4.01$ and $M=3.63$, 
respectively; mean difference $p>.05)$, compared to the plugged in $(M=3.23)$, controlled nonmastery recovering $(M=3.20)$, and non-mastery recovering $(M=3.22)$ profiles $(p$-values $<.05$ for these comparisons). However, differences between the plugged in, controlled non-mastery recovering, and non-mastery recovering profiles were not significant $(p>.05)$. In sum, these results suggest that high or moderate levels of all four recovery experiences is more beneficial than engagement in only certain sets of recovery experiences (e.g., non-mastery recovery).

Evenings characterized by all four recovery experiences were positively related to employees' next-day behaviors. Employees who unplugged in the evening had the highest levels of helping behavior $(M=3.54)$, compared to the plugged in $(M=3.08)$, controlled non-mastery recovering $(M=3.05)$, and non-mastery recovering $(M=2.86)$ profiles (all comparisons $p<$ $.05)$; differences between the latter three profiles were non-significant $(p>.05)$. Employees who moderately unplugged $(M=3.35)$ the night before also exhibited significantly $(p<.05)$ higher helping compared to the non-mastery recovering profiles. That said, differences between the moderately unplugged and the unplugged, plugged in, or controlled non-mastery recovering profiles were not significant $(p>.05)$. A similar pattern emerged when exploring the effects of daily recovery profiles on personal initiative: the unplugged and moderately unplugged profiles were associated with the highest levels of personal initiative $(M=4.06$ and $M=3.65$, respectively; difference between means were $p>.05)$. Once again, evenings characterized by non-mastery recovering were least beneficial as they were associated with the lowest personal initiative $(M=3.29)$; the difference between the non-mastery recovering and unplugged or moderately unplugged profiles were significant $(p<.05)$. Similar to our findings for helping, neither the moderately unplugged nor the non-mastery recovering profiles were significantly different $(p>.05)$ from the plugged in $(M=3.49)$ and controlled non-mastery recovering $(M=$ 
3.40) profiles. Thus, our results suggest that high levels of all experiences (i.e., unplugging) are critical for next-day proactivity. In contrast, the behavioral outcomes associated with nonmastery recovering are akin to remaining plugged in post-work. Thus, mastery-focused activities are imperative when they co-occur with other recovery experiences for next-day work behaviors.

\section{Supplemental Variable-Centered Analyses}

To further highlight the value of examining daily recovery experiences in tandem, we also used a variable-centered approach via multilevel regression analyses (e.g., Gabriel et al., 2015). We within-person centered each recovery experience variable (Enders \& Tofighi, 2007) and entered these as simultaneous predictors of our outcomes; to closely mimic our MLPA tests, we ran each outcome separately. As shown in Table 9, we found limited support for independent effects of each recovery experience on our criteria. For instance, we found some effects for morning sleep quality: evenings characterized by relaxation $(\gamma=.20, p<.01)$ and control $(\gamma=$ $.10, p<.05)$ increased sleep quality, whereas evenings characterized by mastery $(\gamma=-.08, p<$ .05) decreased sleep quality. However, with the exception of the positive impact of mastery on next-day engagement $(\gamma=.06, p<.05)$, no other recovery experience related to well-being (emotional exhaustion and work engagement) or behaviors (helping, personal initiative) in the afternoon. In contrast to the multilevel regression analyses, our MLPA results underscore the value of mastery experiences post-work in conjunction with other recovery experiences. Indeed, higher levels of psychological detachment, relaxation, and control, but not mastery (i.e., nonmastery recovering) in the evenings was uniformly detrimental in terms of lower next-day work engagement, helping behavior, and personal initiative. Thus, our person-centered approach allowed us to demonstrate that employees reap the most benefits when they recover through all experiences (unplugged or moderately unplugged) post-work, rather than a select few. 


\section{Discussion}

In contrast to prior daily studies of employee recovery experiences-which have predominantly adopted a variable-centered approach in considering the singular, and distinct, effects of each recovery experience (e.g., Park et al., 2018; Sonnentag \& Bayer, 2005; Sonnentag \& Binnewies, 2013)—we examined within-person profiles of recovery experiences, their stability over multiple days, and the ability to differentiate these profiles based on their relationships with important antecedents and outcomes. Using ESM data gathered from over 200 employees, we found that: (a) employees engage in different combinations of recovery experiences on a daily basis; (b) daily recovery profiles were dynamic in that over $90 \%$ of all participants were classified in more than one profile during their work week; (c) daily job demands, but not job resources, predicted profile membership; and (d) profiles had key implications for well-being and behaviors. Results of our supplemental analyses provided further support for the examination of daily recovery experiences using a person-centered approach, instead of a variable-centered approach with recovery experiences as separate predictors.

Critically, our findings elucidate the unique combinations of recovery experiences that employees use on a daily basis. This result addresses calls from Sonnentag et al. (2017) that scholars need to focus on recovery experiences beyond just psychological detachment at the daily level, as well as recommendations from Bennett et al. (2016) to consider how recovery experiences occur in conjunction day-to-day. As such, our work represents a critical departure from prior work, shedding light on the unique sets of recovery experiences that individuals utilize daily. Adopting a within-person approach also allowed us to demonstrate the intraindividual variation that typifies daily profile membership, furthering understanding of recovery experiences as dynamic phenomena. Our descriptive analyses illustrated that employees do not 
report the same combination of recovery experiences across the work week; rather, employees seemingly make decisions regarding specific recovery experiences on a daily basis. In fact, we found that daily recovery profile membership exhibits substantial variation in that, on average, employees are unlikely to utilize the same combination of recovery experiences from one day to the next. While theoretically aligning with work that has established fluctuations in daily recovery processes (e.g., Binnewies et al., 2009; Sonnentag, 2003; Sonnentag et al., 2008), these findings also provide an important starting point for future recovery research. More work should consider the dynamics surrounding daily recovery profile membership, such as the factors associated with greater stability in using certain sets of recovery experiences (e.g., non-mastery recovering) versus others (e.g., unplugged). To the extent that the variability in membership differs depending on the specific profile, there are varying levels of within- and between-person components to membership in each profile; future research can also explore these factors.

The present study also extends past work that has predominantly focused on well-being benefits associated with daily recovery (Demerouti et al., 2009; Sonnentag et al., 2017) to highlight implications of profiles of daily recovery experiences for next-day well-being and work behaviors. In so doing, our approach explicates the detriments associated with experiencing high levels of psychological detachment, relaxation, and control, without mastery: evenings characterized by non-mastery recovering were related to lower work engagement, helping, and personal initiative the next day. In fact, for several criteria, non-mastery recovering exhibited deleterious effects that were akin to remaining plugged in post-work. To this end, our results speak to the possibility that daily recovery may be most beneficial when it not only reverses strain reactions through psychological detachment and relaxation, but also when it builds or replaces lost resources through mastery and control (Bennett et al., 2018). Consistent with this 
theorizing, employees who were unplugged or moderately unplugged after hours seemed to reap the greatest benefits in terms of next-day well-being and engagement in discretionary acts. In other words, our person-centered, intra-individual approach to employees' recovery allowed us to establish that employees should have all four recovery experiences post-work-as opposed to a select few-to facilitate next-day well-being and positive work behaviors. Critically, these effects would have been missed with variable-centered analyses (see Supplemental Analyses). Thus, we encourage scholars to continue to explore this area of research, examining whether other well-being and work outcomes benefit from all four recovery experiences. Indeed, it could be the case that some criteria of interest (e.g., helping, personal initiative) require recovery via all four recovery experiences, whereas other criteria (e.g., organizational commitment, positive affect) can stem from certain combinations of recovery experiences only. Alternatively, scholars can also examine whether "dark" workplace behaviors (e.g., incivility, interpersonal aggression) can be inhibited when employees belong to the unplugged profile (i.e., the profile that enhanced helping and personal initiative), or whether different profiles yield effects for this criteria.

Our study also adds to extant knowledge on the impact of job demands and resources on recovery. Our results for job demands largely align with the JD-R model, suggesting that job demands impair daily recovery (Bennett et al., 2018; Kinnunen et al., 2011; Sonnentag \& Fritz, 2007). These findings diverge from theorizing based on ERM, which contends that recovery post-work is crucial following the expenditure of effort to cope with work stressors (Meijman \& Mulder, 1998; Volmer et al., 2012). As such, ERM implicitly suggests that days with higher job demands necessitate recuperation, prompting heightened recovery after hours (e.g., Demerouti et al., 2009). Yet, our findings highlight that job demands impede recovery experiences: days characterized by higher role ambiguity and time pressure made employees more likely to belong 
to the plugged in, controlled non-mastery recovering, moderately unplugged, or non-mastery recovering profiles, compared to the unplugged profile. Thus, our work indicates that employees may remain activated post-work on days with higher job demands, hindering their ability to effectively recover via high levels of all four recovery experiences despite the fact thataccording to the ERM - those days are when effective recovery is most needed. Additionally, given that our findings highlight the necessity in experiencing mastery in conjunction with psychological detachment, relaxation, and control (i.e., the effects of the unplugged profile vs. the non-mastery recovering profile), it is also noteworthy that these results provide preliminary evidence to suggest that coping with daily job demands impairs employees' abilities to experience high levels of mastery alongside the other three recovery experiences in particular. For instance, days with higher role ambiguity increased the likelihood that employees belonged to the controlled non-mastery recovering or non-mastery recovering profiles than the unplugged profile. We encourage research to explore this effect, with an emphasis on job demands and/or resources that may enhance the likelihood that employees engage in profiles with heightened mastery (e.g., higher creative job demands or innovativeness may increase the likelihood that employees are in the unplugged profile; Bakker et al., 2007).

Further, our results indicated that both time pressure and role ambiguity — despite their origins as being more or less beneficial for employee growth, respectively (LePine et al., 2005; Podsakoff et al., 2007)—were similarly prohibitive for employee recovery. This suggests that the beneficial impact of time pressure on daily performance (e.g., Binnewies \& Wörnlein, 2011; Ohly \& Fritz, 2010) may not spill into time spent after work hours; instead, the positive effects may be limited to the workplace and may impair employees' well-being and behaviors the next day. Our findings thus suggest that daily role ambiguity and time pressure are both sources of 
strain when considered intra-individually, preventing employees from mentally disengaging after hours. This is consistent with the between-person perspective on these stressors (e.g., LePine et al., 2005). However, we also agree with researchers who argue that daily stressors, such as time pressure and role ambiguity, may not always match these conceptualizations (e.g., Kühnel, Sonnentag, \& Westman, 2009). Consistent with the recommendations of ESM experts (Gabriel et al., 2018), we believe our results further highlight the importance of testing the extent to which challenge and hindrance stressors are psychometrically isomorphic (i.e., constructs and measures are similar across levels) and the extent to which their relationships with antecedents and consequences are homologous (i.e., relationships are similar across levels).

Finally, we are among the first to adopt a person-centered approach when exploring within-person phenomena such as employee recovery experiences (as a recent exception, see: Diefendorff, Gabriel, Nolan, \& Yang, in press). As such, we depart from prior scholarship that has largely taken a static perspective when utilizing this analytic lens to studying organizational phenomena. In taking an intra-individual person-centered approach to employee recovery experiences in particular, we found evidence of profile structures that uniquely reflect the cooccurrence of daily recovery experiences - while our plugged in and unplugged profiles have conceptual similarities to the "pondering" and "leaving work behind" profiles from Bennett et al. (2016), respectively, the remaining profiles (i.e., controlled non-mastery recovering, moderately unplugged, non-mastery recovering) distinctly capture combinations of recovery experiences that employees exhibit daily. As such, our work highlights that different profile structures may emerge depending on whether a static (i.e., between-person) or dynamic (i.e., within-person) perspective is employed. Given this, we encourage scholars to not only continue to adopt a person-centered lens when exploring organizational phenomena, but to integrate this approach 
with an intra-individual perspective. For instance, although Klotz et al. (2018) examined different profiles of citizenship behavior employees engage in generally, there may be unique combinations of citizenship that employees exhibit daily depending on daily fluctuations in work conditions and interactions; this approach would be consistent with the dynamic foundation of social exchange theory (e.g., Cropanzano \& Mitchell, 2005). Future research could also combine within- and between-person assessments to form profiles, capturing daily- or event-level experiences with trait-level tendencies. Finally, future studies can also consider phenomena that have been established as dynamic, but have yet to be examined from a person-centered approach. As an example, scholars could examine daily profiles of job demands and resources, or various personality traits that have been found to vary daily (e.g., Judge, Simon, Hurst, \& Kelley, 2014).

\section{Practical Implications}

Identifying daily profiles of recovery experiences has important outcomes for employees and supervisors alike. For employees, our results expand upon work by Bennett et al. (2016) in suggesting that employees should consider engaging in combinations of recovery experiences after each workday; that is, employees should not focus on only one type of experience to maximize recovery benefits. Rather, our results suggest that the greatest benefits, in terms of both well-being and work-related behaviors, occur when employees report higher levels of all four recovery experiences daily. This is particularly important, given that our non-mastery recovering profile exhibited high levels of three recovery experiences (i.e., psychological detachment, relaxation, control), yet still did not accrue the same benefits as our unplugged profile. Indeed, even utilizing the four recovery experiences to a moderate extent is more beneficial on a daily basis (i.e., our moderately unplugged profile) than non-mastery recovering. Our results therefore imply that employees should seek opportunities to promote mastery after- 
hours with other recovery experiences. Not only will this aid employees in their well-being the next day at work (e.g., lower emotional exhaustion, higher engagement), but it will yield increased levels of proactivity and helping behaviors. Interestingly, it may be possible for organizations to help facilitate mastery; Google and Intel offer community gardens that give employees an opportunity to engage in mastery activities (Muldoon, 2010), which could be encouraged post-workday.

Our work also highlighted the role that job demands play in profiles of daily recovery experiences. Perhaps counterintuitively, our results suggest that employees who experience time pressure and role ambiguity should recognize that these stressors increase their propensity to engage in suboptimal recovery. Thus, our work is consistent with sentiments expressed by Bennett et al. (2018) that daily job demands keep employees 'activated' post-work. Employees should therefore attempt to adjust their evening habits to offset negative consequences of remaining plugged in to work. Supervisors can play a role in facilitating this process, making sure they signal to employees that time spent recovering after hours is valued (e.g., supervisor support for recovery; Bennett et al., 2016). Our work also fits into broader emerging narratives that organizations should be "turning off" job demands by hindering access to e-mails after hours to minimize work spilling directly into the home environment (e.g., Barber \& Santuzzi, 2015; Butts, Becker, \& Boswell, 2015). Importantly, supervisors aiding employee recovery is likely distinct from daily social support, which had limited effects as an antecedent in our model. As future work continues to build in this area, this would be something to empirically delineate.

Supervisors should also be cognizant of how daily demands at work affect employee recovery. As such, managers should strive to ensure that daily tasks are as clear as possible to mitigate the occurrence of role ambiguity. Further, although time pressure has been posited to be 
a beneficial challenge for employees (Rodell \& Judge, 2009), this effect may not be ubiquitous on a daily basis. Rather, because time pressure can decrease employees' abilities to recover by increasing the likelihood of them remaining plugged in post-work, supervisors should recognize that any gains associated with challenge demands may come with costs to employees' daily recovery experiences. Assuming that supervisors wish for employees to return to work engaged and proactive the next day, this is an important trade-off that needs to be considered for crafting daily work schedules. Through improved supervisor and employee awareness of conditions surrounding effective recovery experiences, organizations and individuals alike may reap benefits in the form of improved employee well-being and proactivity day-to-day.

\section{Limitations and Future Directions}

The current study should be understood in light of its limitations. First, all data was samesource. Importantly, we were interested in employees' personal recovery experiences and their perceptions of well-being and work-related behaviors, making self-report assessments most appropriate. However, we took steps to address the possibility of common method biases by altering the scale anchors and the time referent of measures and utilizing a time-lagged design (Podsakoff et al., 2003). Nonetheless, future work should constructively replicate our work by exploring whether our profiles of daily recovery experiences replicate in addition to examining other theoretically relevant antecedents and outcomes. For instance, researchers could include coworker or supervisor ratings of behaviors to examine how recovery profile membership affects others' perceptions of behaviors at work (e.g., Trougakos, Beal, Cheng, Hideg, \& Zweig, 2015). Given the increased use of wearable technology in research on employee well-being (e.g., Barber, Taylor, Burton, \& Bailey, 2017), future work could also examine how daily profiles of recovery experiences relate to indicators such as daily heart rate variability or objective sleep 
ratings. Further, although our time-lagged analyses suggest that daily recovery experience profile membership impacts next-day well-being, prior work by Mäkikangas et al. (2014) reported reciprocal relationships between these constructs ${ }^{8}$. Thus, as organizational scholarship continues to delve into the relationship between employee recovery experiences and well-being, researchers could explore if there are reciprocal relationships between daily recovery experience profile membership and well-being that create gain spirals (e.g., Halbesleben \& Wheeler, 2015).

Second, although we sought to examine how job resources affect profile membership, we did not find much evidence that social support mattered. One possible explanation is that, despite within-person variability, daily social support is not beneficial unless it is deemed necessary by employees to achieve work-related goals. It could also be the case that other work resources outside of social relationships should be considered. For example, daily perceptions of job control, which is clearly aligned with the JD-R (Bakker \& Demerouti, 2007, 2017) and related to job demands-control models (Karasek, 1979), may be a more fruitful resource to consider. Likewise, scholars could consider resources that may be more likely to correlate with profiles higher in mastery (i.e., our unplugged profile), such as innovativeness, access to information, and feelings of appreciation (e.g., Bakker et al., 2007). Further, our examination of challenge and hindrance stressors was limited to experiences of daily time pressure and role ambiguity, respectively. While we had conceptual, empirical, and practical reasons for selecting these demands, future research should examine whether different forms of challenge (e.g., job responsibility) and hindrance stressors (e.g., interpersonal conflict) exhibit relationships with

\footnotetext{
${ }^{8}$ As suggested by an anonymous reviewer, we explored the possibility of reverse causality in supplemental analyses. Specifically, we examined whether (a) employee well-being (i.e., emotional exhaustion, work engagement) and work behaviors (i.e., helping behaviors, personal initiative) of the prior day $(t-1)$ predict daily recovery experience profile membership $(t)$, and (b) daily recovery experience profile membership (morning of day $t$ ) predicts perceptions of job demands and resources (afternoon of day $t$ ). Analyses revealed limited statistically significant support for these relationships. Findings are available from the first author upon request.
} 
daily recovery profile membership that are distinct from the findings in this study. This can be particularly insightful as scholars can establish whether other types of stressors are similarly prohibitive for daily recovery experiences, or if daily time pressure or role ambiguity are unique in their associations with daily recovery profile membership.

Third, we only focused on recovery in the evening after work during one workweek. As such, we did not examine daily profiles of recovery experiences over longer (e.g., weekends, weeks, months) and shorter (e.g., lunchbreaks, micro-breaks) timeframes, each of which could offer additional insight into employee recovery. For instance, adopting a longer timeframe would allow an examination of cyclical factors that affect employees' recovery experiences week-toweek, uncovering potential patterns surrounding daily recovery experience profile membership, or whether there are certain daily recovery experience profile trajectories across a work week ${ }^{9}$. Conversely, studying profiles during short break episodes could help unpack how ebbs and flows of daily demands predict recovery profiles as an immediate response to work stressors (Trougakos, Hideg, Cheng, \& Beal, 2014). We encourage scholars to explore the dynamics of employees' recovery processes across varying timeframes (see also, Beal \& Gabriel, 2019).

Finally, we were limited in our ability to examine factors that prompt employees' daily transitions from one profile to another. Although our antecedent analyses provide insight into how daily job demands predict daily recovery profile membership, it does not elucidate whether they impact shifts in profile membership. To explore this, scholars can use latent transition analysis (LTA), which examines correlates that are associated with changes in profile membership over time. Importantly, LTA "requires large samples in order to converge on proper, replicated solutions and to achieve reasonable generalizability" (Kam, Morin, Meyer, \&

\footnotetext{
${ }^{9}$ We thank members of the editorial team for these suggestions.
} 
Topolnytsky, 2016, p. 1471). Indeed, studies utilizing LTA have sample sizes ranging between 521-1744 observations at each time point (see Mäkikangas [2018] for an exception); in contrast, our sample size ranged between 189-199 observations each day, which is appropriate for ESM sample sizes (Gabriel et al., 2018), but prohibitive for rigorous LTA. We view each of these extensions of our work as promising future directions for recovery research.

\section{Conclusion}

To date, daily studies of employee recovery processes have examined psychological detachment, relaxation, mastery, and control, in relative isolation. In the current examination, we adopted an intra-individual, person-centered approach, elucidating the unique combinations of recovery experiences utilized daily over one work week. Our findings illustrate the dynamic nature of daily recovery experience profiles, antecedents of daily profile membership, and the impact of these profiles on employees' next-day well-being and work behaviors. Our results underscore the importance of evenings characterized by all four recovery experiences. As such, this study provides greater insight into the complexity surrounding employees' daily recovery processes, and the advantages of examining all four experiences in combination day-to-day. 


\section{References}

Asparouhov, T., \& Muthén, B. (2014a). Auxiliary variables in mixture modeling: Three-step approaches using Mplus. Structural Equation Modeling, 21, 329-341. doi:

10.1080/10705511.2014.915181

Asparouhov, T., \& Muthén, B. (2014b). Auxiliary variables in mixture modeling: Using the $\mathrm{BCH}$ method in Mplus to estimate a distal outcome model and an arbitrary secondary model. Mplus Web Note \#21. Retrieved from https://www.statmodel.com/download/asparouhov_muthen_2014.pdf

Asparouhov T., Muthén B. (2015). Residual associations in latent class and latent transition analysis. Structural Equation Modeling, 22, 169-177. doi:

10.1080/10705511.2014.935844

Bakk, Z., \& Vermunt, J. K. (2016). Robustness of stepwise latent class modeling with continuous distal outcomes. Structural Equation Modeling: A Multidisciplinary Journal, 23, 20-31. doi: 10.1080/10705511.2014.955104

Bakker, A. B., \& Demerouti, E. (2007). The job demands-resources model: State of the art. Journal of Managerial Psychology, 22, 309-328. doi: 10.1108/02683940710733115

Bakker, A. B., \& Demerouti, E. (2017). Job demands-resources theory: Taking stock and looking forward. Journal of Occupational Health Psychology, 22, 273-285. doi: 10.1037/ocp0000056

Bakker, A. B., Hakanen, J. J., Demerouti, E., \& Xanthopoulou, D. (2007). Job resources boost work engagement, particularly when job demands are high. Journal of Educational Psychology, 99, 274-284. doi: 10.1037/0022-0663.99.2.274

Barber, L. K., \& Santuzzi, A. M. (2015). Please respond ASAP: Workplace telepressure and employee recovery. Journal of Occupational Health Psychology, 20, 172-189. doi: $10.1037 / \mathrm{a} 0038278$

Barber, L. K., Taylor, S. G., Burton, J. P., \& Bailey, S. F. (2017). A self-regulatory perspective of work-to-home undermining spillover/crossover: Examining the roles of sleep and exercise. Journal of Applied Psychology, 102, 753-763. doi: 10.1037/apl0000196

Bauer, D. J., \& Curran, P. J. (2003). Distributional assumptions of growth mixture models: Implications for overextraction of latent trajectory classes. Psychological Methods, 8, 338-363. doi: 10.1037/1082-989X.8.3.338

Beal, D. J., \& Gabriel, A. S. (2019). Looking within: An examination, combination, and extension of within-person methods across multiple levels of analysis. In S. E. Humphrey \& J. M. LeBreton (Eds.), The handbook for multilevel theory, measurement, and analysis (pp. 305-327). Washington, DC: American Psychological Association. 
Bennett, A. A., Bakker, A. B., \& Field, J. G. (2018). Recovery from work- related effort: A meta- analysis. Journal of Organizational Behavior, 39, 262-275. doi: 10.1002/job.2217

Bennett, A. A., Gabriel, A. S., Calderwood, C., Dahling, J. J., \& Trougakos, J. P. (2016). Better together? Examining profiles of employee recovery experiences. Journal of Applied Psychology, 101, 1635-1654. doi: 10.1037/ap10000157

Binnewies, C., \& Wörnlein, S. C. (2011). What makes a creative day? A diary study on the interplay between affect, job stressors, and job control. Journal of Organizational Behavior, 32, 589-607. doi: 10.1002/job.731

Binnewies, C., Sonnentag, S., \& Mojza, E. J. (2009). Feeling recovered and thinking about the good sides of one's work. Journal of Occupational Health Psychology, 14, 243-256. doi: $10.1037 / \mathrm{a} 0014933$

Binnewies, C., Sonnentag, S., \& Mojza, E. J. (2010). Recovery during the weekend and fluctuations in weekly job performance: A week- level study examining intra- individual relationships. Journal of Occupational and Organizational Psychology, 83, 419-441. doi: 10.1348/096317909X418049

Biron, M., \& van Veldhoven, M. (2016). When control becomes a liability rather than an asset: Comparing home and office days among part- time teleworkers. Journal of Organizational Behavior, 37, 1317-1337. doi: 10.1002/job.2106

Bolck, A., Croon, M., \& Hagenaars, J. (2004). Estimating latent structure models with categorical variables: One-step versus three-step estimators. Political Analysis, 12, 3-27. doi: 10.1093/pan/mph001

Bono, J. E., Glomb, T. M., Shen, W., Kim, E., \& Koch, A. J. (2013). Building positive resources: Effects of positive events and positive reflection on work stress and health. Academy of Management Journal, 56, 1601-1627. doi: 10.5465/amj.2011.0272

Butts, M. M., Becker, W. J., \& Boswell, W. R. (2015). Hot buttons and time sinks: The effects of electronic communication during nonwork time on emotions and work-nonwork conflict. Academy of Management Journal, 58, 763-788. doi: 10.5465/amj.2014.0170

Buysse, D. J., Reynolds, C. F., Monk, T. H., Berman, S. R., \& Kupfer, D. J. (1989). The Pittsburgh Sleep Quality Index: A new instrument for psychiatric practice and research. Psychiatry Research, 28, 193-213. doi: 10.1016/0165-1781(89)90047-4

Christian, M. S., Eisenkraft, N., \& Kapadia, C. P. (2015). Dynamic associations among somatic complaints, human energy, and discretionary behaviors: Experiences with pain fluctuations at work. Administrative Science Quarterly, 60, 66-102. doi: $10.1177 / 0001839214553655$ 
Crawford, E. R., LePine, J. A., \& Rich, B. L. (2010). Linking job demands and resources to employee engagement and burnout: A theoretical extension and meta-analytic test. Journal of Applied Psychology, 95, 834-848. doi: 10.1037/a0019364

Cropanzano, R., \& Mitchell, M. S. (2005). Social exchange theory: An interdisciplinary review. Journal of Management, 31, 874-900. doi: 10.1177/0149206305279602

Demerouti, E., Bakker, A. B., Geurts, S. A. E., \& Taris, T. W. (2009). Daily recovery from work-related effort during non-work time. In P. L. Perrewé \& D. C. Ganster (Eds.), Research in occupational stress and well-being (Vol. 7, pp. 85-123). Bingley, UK: Emerald Group. doi: 10.1108/S1479-3555(2009)0000007006

Demerouti, E., Bakker, A. B., Sonnentag, S., \& Fullagar, C. J. (2012). Work related flow and energy at work and at home: A study on the role of daily recovery. Journal of Organizational Behavior, 33, 276-295. doi: 10.1002/job.760

Derks, D., van Mierlo, H., \& Schmitz, E. B. (2014). A diary study on work-related smartphone use, psychological detachment and exhaustion: Examining the role of the perceived segmentation norm. Journal of Occupational Health Psychology, 19, 74-84. doi: $10.1037 / \mathrm{a} 0035076$

Diallo, T. M., Morin, A. J., \& Lu, H. (2016). Impact of misspecifications of the latent variancecovariance and residual matrices on the class enumeration accuracy of growth mixture models. Structural Equation Modeling: A Multidisciplinary Journal, 23, 507-531. doi: 10.1080/10705511.2016.1169188

Diallo, T. M., Morin, A. J., \& Lu, H. (2017). Performance of growth mixture models in the presence of time-varying covariates. Behavior Research Methods, 49, 1951-1965. doi: 10.3758/s13428-016-0823-0

Diefendorff, J. M., Gabriel, A. S., Nolan, M. T., \& Yang, J. (in press). Emotion regulation in the context of customer mistreatment and felt affect: An event-based profile approach. Journal of Applied Psychology. Advance online publication. doi: 10.1037/ap10000389

Enders, C. K., \& Tofighi, D. (2007). Centering predictor variables in cross-sectional multilevel models: A new look at an old issue. Psychological Methods, 12, 121-138. doi: 10.1037/1082-989X.12.2.121

Folkman, S., Lazarus, R. S., Gruen, R. J., \& DeLongis, A. (1986). Appraisal, coping, health status, and psychological symptoms. Journal of Personality and Social Psychology, 50, 571-579. doi: 10 .1037/0022-3514.50.3.571

Frese, M., Fay, D., Hilburger, T., Leng, K., \& Tag, A. (1997). The concept of personal initiative: Operationalization, reliability and validity in two German samples. Journal of Occupational and Organizational Psychology, 70, 139-161. doi: 10.1111/j.2044- 


\subsection{7.tb00639.x}

Gabriel, A. S., Campbell, J. T., Djurdjevic, E., Johnson, R. E., \& Rosen, C. C. (2018). Fuzzy profiles: Comparing and contrasting latent profile analysis and fuzzy set qualitative comparative analysis for person-centered research. Organizational Research Methods. Advance online publication. doi: 10.1177/1094428117752466

Gabriel, A. S., Daniels, M. A., Diefendorff, J. M., \& Greguras, G. J. (2015). Emotional labor actors: A latent profile analysis of emotional labor strategies. Journal of Applied Psychology, 100, 863-879. doi: 10.1037/a0037408

Gabriel, A. S., Podsakoff, N. P., Beal, D .J., Scott, B. A., Sonnentag, S., Trougakos, J. P., \& Butts, M. M. (2018). Experience sampling methods: A discussion of critical trends and considerations for scholarly advancement. Organizational Research Methods. Advance online publication.

Halbesleben, J. R., \& Wheeler, A. R. (2015). To invest or not? The role of coworker support and trust in daily reciprocal gain spirals of helping behavior. Journal of Management, 41, 1628-1650. doi: 10.1177/0149206312455246

Hipp, J. R., \& Bauer, D. J. (2006). Local solutions in the estimation of growth mixture models. Psychological Methods, 11, 36-53. doi: 10.1037/1082-989X.11.1.36

Howard, J., Gagné, M., Morin, A. J., \& Van den Broeck, A. (2016). Motivation profiles at work: A self-determination theory approach. Journal of Vocational Behavior, 95, 74-89. doi: 10.1016/j.jvb.2016.07.004

Hülsheger, U. R., Lang, J. W., Depenbrock, F., Fehrmann, C., Zijlstra, F. R., \& Alberts, H. J. (2014). The power of presence: The role of mindfulness at work for daily levels and change trajectories of psychological detachment and sleep quality. Journal of Applied Psychology, 99, 1113-1128. doi: 10.1037/a0037702

Judge, T. A., Simon, L. S., Hurst, C., \& Kelley, K. (2014). What I experienced yesterday is who I am today: Relationship of work motivations and behaviors to within-individual variation in the five-factor model of personality. Journal of Applied Psychology, 99, 199221. doi: $10.1037 / \mathrm{a} 0034485$

Jung, T., \& Wickrama, K. (2008). An introduction to latent class growth analysis and growth mixture modeling. Social and Personality Psychology Compass, 2, 302-317. doi: 10.1111/j.1751-9004.2007 .00054.x

Kam, C., Morin, A. J., Meyer, J. P., \& Topolnytsky, L. (2016). Are commitment profiles stable and predictable? A latent transition analysis. Journal of Management, 42, 1462-1490. doi: $10.1177 / 0149206313503010$

Karasek, R. A. (1979). Job demands, job decision latitude, and mental strain: Implications for job 
redesign. Administrative Science Quarterly, 24, 285-308. doi: 10.2307/2392498

Kinnunen, U., \& Feldt, T. (2013). Job characteristics, recovery experiences and occupational well-being: Testing cross-lagged relationships across 1 year. Stress and Health: Journal of the International Society for the Investigation of Stress, 29, 369-382. doi: 10.1002/smi.2483

Kinnunen, U., Feldt, T., Siltaloppi, M., \& Sonnentag, S. (2011). Job demands-Resources model in the context of recovery: Testing recovery experiences as mediators. European Journal of Work and Organizational Psychology, 20, 805-832. doi: 10.1080/1359432X .2010 .524411

Klotz, A. C., Bolino, M. C., Song, H., \& Stornelli, J. (2018). Examining the nature, causes, and consequences of profiles of organizational citizenship behavior. Journal of Organizational Behavior, 39, 629-647. doi: 10.1002/job.2259

Kühnel, J., Sonnentag, S., \& Bledow, R. (2012). Resources and time pressure as day- level antecedents of work engagement. Journal of Occupational and Organizational Psychology, 85, 181-198. doi: 10.1111/j.2044-8325.2011.02022.x

Kühnel, J., Sonnentag, S., \& Westman, M. (2009). Does work engagement increase after a short respite? The role of job involvement as a double- edged sword. Journal of Occupational and Organizational Psychology, 82, 575-594. doi: 10.1348/096317908X349362

Lanaj, K., Johnson, R. E., \& Barnes, C. M. (2014). Beginning the workday yet already depleted? Consequences of late-night smartphone use and sleep. Organizational Behavior and Human Decision Processes, 124, 11-23. doi: 10.1016/j.obhdp.2014.01.001

Lanza, S. T., Tan, X., \& Bray, B. C. (2013). Latent class analysis with distal outcomes: A flexible model-based approach. Structural Equation Modeling, 20, 1-26. doi: 10.1080/10705511.2013.742377

Lee, K., \& Allen, N. J. (2002). Organizational citizenship behavior and workplace deviance: The role of affect and cognitions. Journal of Applied Psychology, 87, 131-142. doi: 10.1037/0021-9010.87.1.131

LePine, J. A., LePine, M. A., \& Saul, J. R. (2007). Relationships among work and non-work challenge and hindrance stressors and non-work and work criteria: A model of crossdomain stressor effects. In P. Perrewe, \& D. C. Ganster (Eds.), In Research in occupational stress and well being (Vol. 6, pp. 35-73). Oxford, UK: JAI Press.

LePine, J. A., Podsakoff, N. P., \& LePine, M. A. (2005). A meta-analytic test of the challenge stressor-hindrance stressor framework: An explanation for inconsistent relationships among stressors and performance. Academy of Management Journal, 48, 764-775. doi: $10.5465 /$ AMJ.2005.18803921 
Lo, Y., Mendell, N. R., \& Rubin, D. B. (2001). Testing the number of components in a normal mixture. Biometrika, 88, 767-778. doi: 10.1093/biomet/88.3.767

Mäkikangas, A. (2018). Job crafting profiles and work engagement: A person-centered approach. Journal of Vocational Behavior, 106, 101-111. doi: 10.1016/j.jvb.2018.01.001

Mäkikangas, A., Kinnunen, S., Rantanen, J., Mauno, S., Tolvanen, A., \& Bakker, A. B. (2014). Association between vigor and exhaustion during the workweek: A person-centered approach to daily assessments. Anxiety, Stress, \& Coping, 27, 555-575. doi: 10.1080/10615806.2013.860968

Mäkikangas, A., Tolvanen, A., Aunola, K., Feldt, T., Mauno, S., \& Kinnunen, U. (2018). Multilevel latent profile analysis with covariates: Identifying job characteristics profiles in hierarchical data as an example. Organizational Research Methods, 21, 931-954. doi: $10.1177 / 1094428118760690$

Marcus, B., Weigelt, O., Hergert, J., Gurt, J., \& Gelléri, P. (2017). The use of snowball sampling for multi source organizational research: Some cause for concern. Personnel Psychology, 70, 635-673. doi: 10.1111/peps.12169

Marsh, H. W., Lüdtke, O., Trautwein, U., \& Morin, A. J. S. (2009). Classical latent profile analysis of academic self-concept dimensions: Synergy of person- and variable-centered approaches to theoretical models of self-concept. Structural Equation Modeling, 16, 191225. doi: 10.1080/10705510902751010

Meijman, T. F., \& Mulder, G. (1998). Psychological aspects of workload. In P. J. D. Drenth \& C. J. de Wolff (Eds.), Handbook of work and organizational psychology, Vol. 2: Work psychology (pp. 5-33). Hove, UK: Psychology Press.

Michel, A., Turgut, S., Hoppe, A., \& Sonntag, K. (2016). Challenge and threat emotions as antecedents of recovery experiences: Findings from a diary study with blue-collar workers. European Journal of Work and Organizational Psychology, 25, 674-689. doi: 10.1080/1359432X.2015.1128414

Mojza, E. J., Lorenz, C., Sonnentag, S., \& Binnewies, C. (2010). Daily recovery experiences: The role of volunteer work during leisure time. Journal of Occupational Health Psychology, 15, 60-74. doi: 10.1037/a0017983

Morin, A. J., \& Marsh, H. W. (2015). Disentangling shape from level effects in person-centered analyses: An illustration based on university teachers' multidimensional profiles of effectiveness. Structural Equation Modeling: A Multidisciplinary Journal, 22, 39-59.doi: 10.1080/10705511.2014.919825

Morin, A. J. S., Meyer, J. P., Creusier, J., \& Biétry, F. (2016). Multiplegroup analysis of similarity in latent profile solutions. Organizational Research Methods, 19, 231-254. doi: $10.1177 / 1094428115621148$ 
Morin, A. J., Boudrias, J. S., Marsh, H. W., McInerney, D. M., Dagenais-Desmarais, V., Madore, I., \& Litalien, D. (2017). Complementary variable-and person-centered approaches to the dimensionality of psychometric constructs: Application to psychological wellbeing at work. Journal of Business and Psychology, 32, 395-419. doi: 10.1007/s10869-016-94487

Muldoon, K. (2010, June 18). At Hillsboro's Intel, the community garden is a company perk with a purpose. The Oregonian. Retrieved from http://blog.oregonlive.com

Muthén, L. K., \& Muthén, B. O. (1998-2015). Mplus user's guide. Los Angeles, CA: Muthén \& Muthén.

Nylund, K. L., Asparouhov, T., \& Muthén, B. O. (2007). Deciding on the number of classes in latent class analysis and growth mixture modeling: A Monte Carlo simulation study. Structural Equation Modeling, 14, 535-569. doi: 10.1080/10705510701575396

Ohly, S., \& Fritz, C. (2010). Work characteristics, challenge appraisal, creativity, and proactive behavior: A multi- level study. Journal of Organizational Behavior, 31, 543-565. doi: 10.1002/job.633

Park, Y., Fritz, C., \& Jex, S. M. (2018). Daily cyber incivility and distress: The moderating roles of resources at work and home. Journal of Management, 44, 2535-2557. doi: $10.1177 / 0149206315576796$

Peugh, J., \& Fan, X. (2013). Modeling unobserved heterogeneity using latent profile analysis: A Monte Carlo simulation. Structural Equation Modeling: A Multidisciplinary Journal, 20, 616-639. doi: 10.1080/10705511.2013.824780

Peugh, J., \& Fan, X. (2015). Enumeration index performance in generalized growth mixture models: A Monte Carlo test of Muthén's (2003) hypothesis. Structural Equation Modeling: A Multidisciplinary Journal, 22, 115-131. doi: 10.1080/10705511.2014.919823

Podsakoff, N. P., LePine, J. A., \& LePine, M. A. (2007). Differential challenge stressorhindrance stressor relationships with job attitudes, turnover intentions, turnover, and withdrawal behavior: A meta-analysis. Journal of Applied Psychology, 92, 438-454. doi: 10.1037/0021-9010.92.2.438

Podsakoff, N. P., Spoelma, T. M., Chawla, N., \& Gabriel, A. S. (2019). What predicts withinperson variance in applied psychology constructs? An empirical examination. Journal of Applied Psychology. Advance online publication. doi: 10.1037/apl0000374

Podsakoff, P. M., MacKenzie, S. B., Lee, J.-Y., \& Podsakoff, N. P. (2003). Common method biases in behavioral research: A critical review of the literature and recommended remedies. Journal of Applied Psychology, 88, 879-903. doi: 10.1037/0021-9010.88.5.879 
Rodell, J. B., \& Judge, T. A. (2009). Can "good" stressors spark "bad" behaviors? The mediating role of emotions in links of challenge and hindrance stressors with citizenship and counterproductive behaviors. Journal of Applied Psychology, 94, 1438-1451. doi: $10.1037 / \mathrm{a} 0016752$

Rosen, C. C., Koopman, J., Gabriel, A. S., \& Johnson, R. E. (2016). Who strikes back? A daily investigation of when and why incivility begets incivility. Journal of Applied Psychology, 101, 1620-1634. doi: 10.1037/ap10000140

Schaufeli, W. B., Bakker, A. B., \& Salanova, M. (2006). The measurement of work engagement with a short questionnaire: A cross-national study. Educational and Psychological Measurement, 66, 701-716. doi: 10.1177/0013164405282471

Scott, B. A., Colquitt, J. A., Paddock, E. L., \& Judge, T. A. (2010). A daily investigation of the role of manager empathy on employee well-being. Organizational Behavior and Human Decision Processes, 113, 127-140. doi: 10.1016/j.obhdp.2010.08.001

Siltaloppi, M., Kinnunen, U., \& Feldt, T. (2009). Recovery experiences as moderators between psychosocial work characteristics and occupational well-being. Work \& Stress, 23, 330348. doi: 10.1080/02678370903415572

Siltaloppi, M., Kinnunen, U., Feldt, T., \& Tolvanen, A. (2011). Identifying patterns of recovery experiences and their links to psychological outcomes across one year. International Archives of Occupational and Environmental Health, 84, 877-888. doi: 10.1007/s00420011-0672-1

Sonnentag, S. (2001). Work, recovery activities, and individual well-being: A diary study. Journal of Occupational Health Psychology, 6, 196-210. doi: 10.1037/10768998.6.3.196

Sonnentag, S. (2003). Recovery, work engagement, and proactive behavior: A new look at the interface between nonwork and work. Journal of Applied Psychology, 88, 518-528. doi: 10.1037/0021-9010.88.3.518

Sonnentag, S. (2015). Dynamics of well-being. Annual Review of Organizational Psychology and Organizational Behavior, 2, 261-293. doi: 10.1146/annurev-orgpsych-032414111347

Sonnentag, S., \& Bayer, U. V. (2005). Switching off mentally: Predictors and consequences of psychological detachment from work during off-job time. Journal of Occupational Health Psychology, 10, 393-414. doi: 10.1037/1076-8998.10.4.393

Sonnentag, S., \& Binnewies, C. (2013). Daily affect spillover from work to home: Detachment from work and sleep as moderators. Journal of Vocational Behavior, 83, 198-208. doi: 10.1016/j.jvb.2013.03.008 
Sonnentag, S., \& Fritz, C. (2007). The Recovery Experience Questionnaire: Development and validation of a measure for assessing recuperation and unwinding from work. Journal of Occupational Health Psychology, 12, 204 -221. doi: 10.1037/1076-8998.12.3.204

Sonnentag, S., \& Fritz, C. (2015). Recovery from job stress: The stressor-detachment model as an integrative framework. Journal of Organizational Behavior, 36, 72-103. doi: 10.1002/job.1924

Sonnentag, S., \& Jelden, S. (2009). Job stressors and the pursuit of sport activities: A day-level perspective. Journal of Occupational Health Psychology, 14, 165-181. doi: $10.1037 / \mathrm{a} 0014953$

Sonnentag, S., \& Kruel, U. (2006). Psychological detachment from work during off-job time: The role of job stressors, job involvement, and recovery-related self-efficacy. European Journal of Work and Organizational Psychology, 15, 197-217. doi: 10.1080/13594320500513939

Sonnentag, S., \& Natter, E. (2004). Flight attendants' daily recovery from work: Is there no place like home? International Journal of Stress Management, 11, 366-391. doi: 10.1037/1072-5245.11.4.366

Sonnentag, S., \& Zijlstra, F. R. (2006). Job characteristics and off-job activities as predictors of need for recovery, well-being, and fatigue. Journal of Applied Psychology, 91, 330-350. doi: 10.1037/0021-9010.91.2.330

Sonnentag, S., Binnewies, C., \& Mojza, E. J. (2008). "Did you have a nice evening?" A daylevel study on recovery experiences, sleep, and affect. Journal of Applied Psychology, 93, 674-684. doi: 10.1037/0021-9010.93.3.674

Sonnentag, S., Mojza, E. J., Demerouti, E., \& Bakker, A. B. (2012). Reciprocal relations between recovery and work engagement: The moderating role of job stressors. Journal of Applied Psychology, 97, 842-853. doi: 10.1037/a0028292

Sonnentag, S., Venz, L., \& Casper, A. (2017). Advances in recovery research: What have we learned? What should be done next? Journal of Occupational Health Psychology, 22, 365-380. doi: 10.1037/ocp0000079

Tadić Vujčić, M., Oerlemans, W. G., \& Bakker, A. B. (2017). How challenging was your work today? The role of autonomous work motivation. European Journal of Work and Organizational Psychology, 26, 81-93. doi: 10.1080/1359432X.2016.1208653

ten Brummelhuis, L. L., \& Bakker, A. B. (2012). Staying engaged during the week: The effect of off-job activities on next day work engagement. Journal of Occupational Health Psychology, 17, 445-455. doi: 10.1037/a0029213 
Trougakos, J. P., Beal, D. J., Cheng, B. H., Hideg, I., \& Zweig, D. (2015). Too drained to help: A resource depletion perspective on daily interpersonal citizenship behaviors. Journal of Applied Psychology, 100, 227-236. doi: 10.5465/10.1037/a0038082

Trougakos, J. P., Hideg, I., Cheng, B. H., \& Beal, D. J. (2014). Lunch breaks unpacked: The role of autonomy as a moderator of recovery during lunch. Academy of Management Journal, 57, 405-421. doi: 10.5465/amj.2011.1072

Tuckey, M. R., Searle, B., Boyd, C. M., Winefield, A. H., \& Winefield, H. R. (2015). Hindrances are not threats: Advancing the multidimensionality of work stress. Journal of Occupational Health Psychology, 20, 131-147. doi: 10.5465/10.1037/a0038280

van Wijhe, C., Peeters, M., Schaufeli, W., \& Ouweneel, E. (2013). Rise and shine: Recovery experiences of workaholic and nonworkaholic employees. European Journal of Work and Organizational Psychology, 22, 476-489. doi: 10.1080/1359432X.2012.663527

Volman, F. E., Bakker, A. B., \& Xanthopoulou, D. (2013). Recovery at home and performance at work: A diary study on self-family facilitation. European Journal of Work and Organizational Psychology, 22, 218-234. doi: 10.1080/1359432X.2011.648375

Volmer, J., Binnewies, C., Sonnentag, S., \& Niessen, C. (2012). Do social conflicts with customers at work encroach upon our private lives? A diary study. Journal of Occupational Health Psychology, 17, 304-315. doi: 10.1037/a0028454

Wang, M., \& Hanges, P. J. (2011). Latent class procedures: Applications to organizational research. Organizational Research Methods, 14, 24-31. doi: 10.1177/1094428110383988

Wharton, A. S. (1993). The affective consequences of service work: Managing emotions on the job. Work and Occupations, 20, 205-232. doi: 10.1177/0730888493020002004

Yang, J., \& Diefendorff, J. M. (2009). The relations of daily counterproductive workplace behavior with emotions, situational antecedents, and personality moderators: A diary study in Hong Kong. Personnel Psychology, 62, 259-295. doi: 10.1111/j.17446570.2009.01138.x

Zijlstra, F. R., \& Sonnentag, S. (2006). After work is done: Psychological perspectives on recovery from work. European Journal of Work and Organizational Psychology, 15, 129-138. doi: 10.1080/13594320500513855

Zimet, G. D., Dahlem, N. W., Zimet, S. G., \& Farley, G. K. (1988). The multidimensional scale of perceived social support. Journal of Personality Assessment, 52, 30-41. doi: 10.1207/s15327752jpa5201_2 


\section{Table 1}

Variance Decomposition for Variables

\begin{tabular}{lccc}
\hline \multicolumn{1}{c}{ Variable } & $\begin{array}{c}\text { Within-Person } \\
\text { Variance }\left(\sigma^{2}\right)\end{array}$ & $\begin{array}{c}\text { Petween-Person } \\
\text { Variance }\left(\tau_{00}\right)\end{array}$ & $\begin{array}{c}\text { Within-Person } \\
\text { Variance }\end{array}$ \\
\hline Morning Survey & & & $52.0 \%$ \\
\hline Psychological Detachment & .66 & .61 & $62.0 \%$ \\
Relaxation & .80 & .49 & $47.9 \%$ \\
Mastery & .57 & .62 & $57.6 \%$ \\
Control & .61 & .45 & $73.3 \%$ \\
Sleep Quality & .66 & .24 & $33.6 \%$ \\
Emotional Exhaustion & .39 & .77 & $31.5 \%$ \\
\hline Afternoon Survey & & & $36.1 \%$ \\
\hline Emotional Exhaustion & .40 & .87 & $58.3 \%$ \\
Role Ambiguity & .26 & .46 & $47.7 \%$ \\
Time Pressure & .81 & .58 & $40.7 \%$ \\
Social Support & .63 & .69 & $35.2 \%$ \\
Work Engagement & .24 & .35 & $39.7 \%$ \\
Helping Behavior & .32 & .59 & .44 \\
Personal Initiative & .29 & &
\end{tabular}

Note. $N=891-967$. Percentage of within-person variance was calculated using the following formula: $\sigma^{2} /\left(\sigma^{2}+\tau_{00}\right)$. 


\section{Table 2}

Means, Standard Deviations, and Correlations of Study Variables

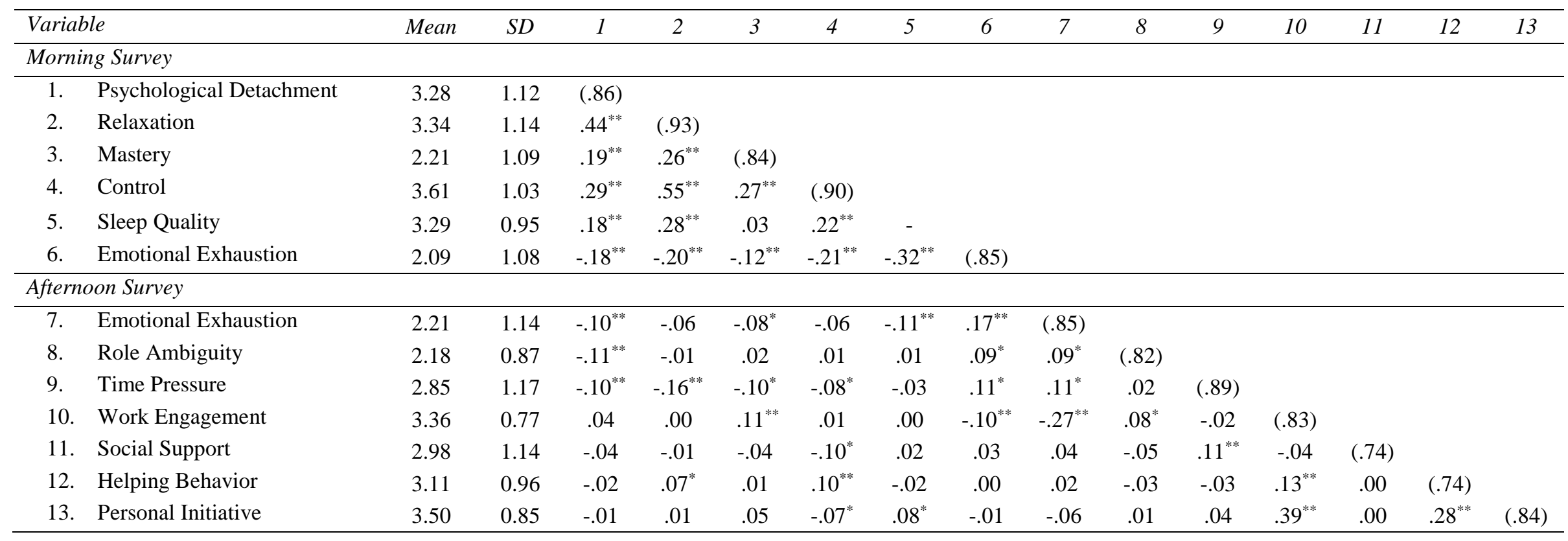

Note. Level $1 n=697-967$ (after accounting for lagged data); Level $2 n=207$. $S D=$ standard deviation. Average reliability across days is along the diagonal. Correlations among the Level 1 variables are within-person centered correlations. Recovery experiences were assessed with reference to the prior evening. Job demands (i.e., role ambiguity and time pressure) and resources (i.e., social support) were modeled during the afternoon of the prior workday $(t-1)$, with profiles of daily recovery experiences during the morning of day $t$. Well-being and workplace behaviors were modeled both the morning and afternoon of day $t$ (please see Analytic Approach for more details).

${ }^{*} p<.05{ }^{* *} p<.01$. 


\section{Table 3}

Latent Profile Enumeration Fit Statistics (Research Question 1)

\begin{tabular}{ccccccccc}
\hline \# of Profiles & $L L$ & $F P$ & AIC & BIC & SSA-BIC & CAIC & LMR $(p)$ & Entropy \\
\hline 2 & -5399.813 & 13 & 10825.625 & 10888.990 & 10847.702 & 10901.990 & 0.0000 & 0.789 \\
3 & -5324.319 & 18 & 10684.637 & 10772.373 & 10715.205 & 10790.373 & 0.0279 & 0.707 \\
4 & -5271.537 & 23 & 10589.073 & 10701.180 & 10628.132 & 10724.180 & 0.4507 & 0.707 \\
5 & -5221.951 & 28 & 10499.902 & 10636.380 & 10547.452 & 10664.380 & 0.0310 & 0.737 \\
6 & -5191.810 & 33 & 10449.621 & 10610.469 & 10505.662 & 10643.469 & 0.0220 & 0.766 \\
7 & -5159.948 & 38 & 10395.896 & 10581.116 & 10460.428 & 10619.116 & 0.1220 & 0.745 \\
8 & -5141.402 & 43 & 10368.803 & 10578.394 & 10441.826 & 10621.394 & 0.6640 & 0.753 \\
9 & -5088.955 & 48 & 10273.911 & 10507.872 & 10355.425 & 10555.872 & 0.4321 & 0.838 \\
\hline
\end{tabular}

Note. Level $1 n=967$; Level $2 n=207 . \mathrm{LL}=\log$-likelihood; FP = free parameters; AIC = Akaike information criteria; $\mathrm{BIC}=$ Bayesian information criteria; SSA-BIC = sample-size adjusted BIC; CAIC = consistent AIC; LMR = Lo, Mendell, and Rubin (2001) test. CAIC is calculated by adding the number of free parameters to the BIC value. 


\section{Table 4}

Descriptive Information for Within-Person Latent Recovery Profiles (Research Question 1)

\begin{tabular}{|c|c|c|c|c|c|c|c|c|c|}
\hline \multirow[t]{2}{*}{ Profile } & \multirow[t]{2}{*}{$\begin{array}{c}\% \text { of } \\
\text { Evenings }\end{array}$} & \multicolumn{2}{|c|}{$\begin{array}{c}\text { Psychological } \\
\text { Detachment }\end{array}$} & \multicolumn{2}{|c|}{ Relaxation $M$} & \multicolumn{2}{|c|}{ Mastery M } & \multicolumn{2}{|c|}{ Control M } \\
\hline & & $M$ & $95 \% \mathrm{CI}$ & $M$ & $95 \% \mathrm{CI}$ & $M$ & $95 \% \mathrm{CI}$ & $M$ & $95 \% \mathrm{CI}$ \\
\hline Plugged In & $21.1 \%$ & 2.31 & {$[2.14,2.48]$} & 1.85 & {$[1.60,2.10]$} & 1.67 & {$[1.52,1.82]$} & 2.38 & {$[2.07,2.70]$} \\
\hline Controlled Non-Mastery Recovering & $28.6 \%$ & 3.01 & {$[2.69,3.34]$} & 2.95 & {$[2.57,3.34]$} & 1.69 & {$[1.52,1.85]$} & 3.50 & {$[3.17,3.83]$} \\
\hline Moderately Unplugged & $19.7 \%$ & 3.31 & {$[3.15,3.47]$} & 3.68 & {$[3.52,3.85]$} & 3.29 & {$[3.16,3.42]$} & 3.87 & {$[3.70,4.04]$} \\
\hline Non-Mastery Recovering & $22.6 \%$ & 4.08 & {$[3.84,4.32]$} & 4.45 & {$[4.23,4.68]$} & 1.73 & {$[1.60,1.86]$} & 4.32 & {$[4.18,4.45]$} \\
\hline Unplugged & $8.0 \%$ & 4.43 & {$[4.22,4.64]$} & 4.71 & {$[4.58,4.84]$} & 4.17 & {$[3.86,4.48]$} & 4.62 & {$[4.48,4.77]$} \\
\hline
\end{tabular}

Note. $M=$ Mean; $\mathrm{CI}=$ Confidence interval. All variables rated on a 5 -point scale $(1=$ not at all; $5=$ very much $)$. 


\section{Table 5}

Profile Membership Across Days (Research Question 2)

\begin{tabular}{|c|c|c|c|}
\hline Profile membership & $\begin{array}{c}\text { Percentage of } \\
\text { individuals }\end{array}$ & Profile membership & $\begin{array}{c}\text { Percentage of } \\
\text { individuals }\end{array}$ \\
\hline One profile & $(9.7 \%)$ & Three profiles & $(35.8 \%)$ \\
\hline Plugged In & $2.9 \%$ & Plugged In, Controlled Non-Mastery Recovering, Moderately Unplugged & $9.2 \%$ \\
\hline Controlled Non-Mastery Recovering & $1.5 \%$ & Plugged In, Controlled Non-Mastery Recovering, Non-Mastery Recovering & $9.2 \%$ \\
\hline Moderately Unplugged & $2.4 \%$ & Plugged In, Moderately Unplugged, Non-Mastery Recovering & $2.4 \%$ \\
\hline Non-Mastery Recovering & $1.0 \%$ & Plugged In, Moderately Unplugged, Unplugged & $1.9 \%$ \\
\hline Unplugged & $1.9 \%$ & $\begin{array}{l}\text { Controlled Non-Mastery Recovering, Moderately Unplugged, Non-Mastery } \\
\text { Recovering }\end{array}$ & $4.4 \%$ \\
\hline Two profiles & $(50.7 \%)$ & Controlled Non-Mastery Recovering, Moderately Unplugged, Unplugged & $1.0 \%$ \\
\hline Plugged In and Controlled non-mastery recovering & $14.5 \%$ & Controlled Non-Mastery Recovering, Non-Mastery Recovering, Unplugged & $3.4 \%$ \\
\hline Plugged In and Moderately Unplugged & $4.4 \%$ & Moderately Unplugged, Non-Mastery Recovering, Unplugged & $4.4 \%$ \\
\hline Plugged In and Non-Mastery Recovering & $3.4 \%$ & Four profiles & $(3.9 \%)$ \\
\hline Plugged In and Unplugged & $1.0 \%$ & $\begin{array}{l}\text { Plugged In, Controlled Non-Mastery Recovering, Moderately Unplugged, Non- } \\
\text { Mastery Recovering }\end{array}$ & $2.4 \%$ \\
\hline Controlled Non-Mastery Recovering and Moderately Unplugged & $6.3 \%$ & $\begin{array}{l}\text { Plugged In, Controlled Non-Mastery Recovering, Moderately Unplugged, } \\
\text { Unplugged }\end{array}$ & $0.5 \%$ \\
\hline Controlled Non-Mastery Recovering and Non-Mastery Recovering & $9.7 \%$ & $\begin{array}{l}\text { Controlled Non-Mastery Recovering, Moderately Unplugged, Non-Mastery } \\
\text { Recovering, Unplugged }\end{array}$ & $1.0 \%$ \\
\hline Controlled Non-Mastery Recovering and Unplugged & $0.5 \%$ & & \\
\hline Moderately Unplugged and Non-Mastery Recovering & $4.8 \%$ & & \\
\hline Moderately Unplugged and Unplugged & $4.4 \%$ & & \\
\hline Non-Mastery Recovering and Unplugged & $1.9 \%$ & & \\
\hline
\end{tabular}

Note. $N=207$. The percentage total next to each label indicates the percent of individuals (compared to the total sample) that belonged to one, two, three, or four profiles across five days of the study. Discrepancies in the totals are attributable to rounding error. Values in parentheses represent sums in that profile category (i.e., one profile). 


\section{Table 6}

Day-to-Day Changes in Profile Membership (Research Question 2)

\begin{tabular}{|c|c|c|c|c|c|c|}
\hline $\begin{array}{l}\text { Profile membership on } \\
\text { former day }\end{array}$ & $\begin{array}{l}\text { Profile membership on } \\
\text { next day }\end{array}$ & $\begin{array}{c}\text { Day } 1 \rightarrow \text { Day } 2 \\
(n=177)\end{array}$ & $\begin{array}{c}\text { Day } 2 \rightarrow \text { Day } 3 \\
(n=186)\end{array}$ & $\begin{array}{c}\text { Day } 3 \rightarrow \text { Day } 4 \\
(n=183)\end{array}$ & $\begin{array}{c}\text { Day } 4 \rightarrow \text { Day } 5 \\
(n=184)\end{array}$ & Average \\
\hline \multicolumn{7}{|l|}{ Plugged In } \\
\hline & Plugged In & $5.7 \%(35.7 \%)$ & $8.6 \%(47.1 \%)$ & $13.1 \%(50.0 \%)$ & $9.2 \%(42.5 \%)$ & $43.8 \%(6.2 \%)$ \\
\hline & $\begin{array}{l}\text { Controlled Non-Mastery } \\
\text { Recovering }\end{array}$ & $4.0 \%(25.0 \%)$ & $5.4 \%(29.4 \%)$ & $6.0 \%(22.9 \%)$ & $7.6 \%(35.0 \%)$ & $28.1 \%(5.4 \%)$ \\
\hline & Moderately Unplugged & $3.4 \%(21.4 \%)$ & $2.7 \%(14.7 \%)$ & $4.4 \%(16.7 \%)$ & $2.7 \%(12.5 \%)$ & $16.3 \%(3.8 \%)$ \\
\hline & Non-Mastery Recovering & $2.3 \%(14.3 \%)$ & $1.6 \%(8.8 \%)$ & $1.6 \%(6.3 \%)$ & $1.6 \%(7.5 \%)$ & $9.2 \%(3.5 \%)$ \\
\hline & Unplugged & $0.6 \%(3.6 \%)$ & $0 \%(0 \%)$ & $1.1 \%(4.2 \%)$ & $0.5 \%(2.5 \%)$ & $2.6 \%(1.8 \%)$ \\
\hline & Total & $15.8 \%(100 \%)$ & $18.0 \%(100 \%)$ & $26.2 \%(100 \%)$ & $21.7 \%(100 \%)$ & \\
\hline \multicolumn{7}{|l|}{$\begin{array}{l}\text { Controlled Non-Mastery } \\
\text { Recovering }\end{array}$} \\
\hline & Plugged In & $6.2 \%(21.6 \%)$ & $9.7 \%(30.5 \%)$ & $4.4 \%(17.8 \%)$ & $6.0 \%(20.4 \%)$ & $22.6 \%(5.5 \%)$ \\
\hline & $\begin{array}{l}\text { Controlled Non-Mastery } \\
\text { Recovering }\end{array}$ & $12.4 \%(43.1 \%)$ & $13.4 \%(42.4 \%)$ & $12.6 \%(51.1 \%)$ & $13.6 \%(46.3 \%)$ & $45.7 \%(4.0 \%)$ \\
\hline & Moderately Unplugged & $3.4 \%(11.8 \%)$ & $2.7 \%(8.5 \%)$ & $2.7 \%(11.1 \%)$ & $4.4 \%(14.8 \%)$ & $11.5 \%(2.6 \%)$ \\
\hline & Non-Mastery Recovering & $6.2 \%(21.6 \%)$ & $5.4 \%(17.0 \%)$ & $4.4 \%(17.8 \%)$ & $3.8 \%(13.0 \%)$ & $17.3 \%(3.5 \%)$ \\
\hline & Unplugged & $0.6 \%(2 \%)$ & $0.5 \%(1.7 \%)$ & $0.6 \%(2.2 \%)$ & $1.6 \%(5.6 \%)$ & $2.9 \%(1.8 \%)$ \\
\hline & Total & $28.8 \%(100 \%)$ & $31.7 \%(100 \%)$ & $24.6 \%(100 \%)$ & $29.4 \%(100 \%)$ & \\
\hline \multicolumn{7}{|l|}{ Moderately Unplugged } \\
\hline & Plugged In & $2.8 \%(12.5 \%)$ & $4.3 \%(23.5 \%)$ & $2.2 \%(10.8 \%)$ & $3.8 \%(17.5 \%)$ & $16.1 \%(5.7 \%)$ \\
\hline & $\begin{array}{l}\text { Controlled Non-Mastery } \\
\text { Recovering }\end{array}$ & $6.2 \%(27.5 \%)$ & $1.6 \%(8.8 \%)$ & $5.5 \%(27.0 \%)$ & $2.2 \%(10.0 \%)$ & $18.3 \%(10.3 \%)$ \\
\hline & Moderately Unplugged & $6.8 \%(30.0 \%)$ & $9.1 \%(50.0 \%)$ & $9.8 \%(48.7 \%)$ & $9.8 \%(45.0 \%)$ & $43.4 \%(9.2 \%)$ \\
\hline & Non-Mastery Recovering & $5.1 \%(22.5 \%)$ & $2.2 \%(11.8 \%)$ & $1.6 \%(8.1 \%)$ & $1.6 \%(7.5 \%)$ & $12.5 \%(7.0 \%)$ \\
\hline & Unplugged & $1.7 \%(7.5 \%)$ & $1.1 \%(5.9 \%)$ & $1.1 \%(5.4 \%)$ & $4.4 \%(20.0 \%)$ & $9.7 \%(6.9 \%)$ \\
\hline & Total & $22.6 \%(100 \%)$ & $18.3 \%(100 \%)$ & $20.2 \%(100 \%)$ & $21.7 \%(100 \%)$ & \\
\hline
\end{tabular}

Note. Due to missing data, the sample sizes assessing patterns of profile membership across consecutive days varied ( $n$ = 177-186). Percentages were calculated based on the sample size of participants who provided data for two consecutive days; discrepancies in the total values are attributed to rounding errors. Averages were calculated based on the percentage of employees in the specific pair of daily recovery profiles, out of those employees who belonged to the target profile on day $t$; standard deviations are reported in parentheses. 


\section{Table 6}

Day-to-Day Changes in Profile Membership (Research Question 2; Continued)

\begin{tabular}{|c|c|c|c|c|c|c|}
\hline \multicolumn{7}{|l|}{ Non-Mastery Recovering } \\
\hline & Plugged In & $4.5 \%(16.3 \%)$ & $2.7 \%(10.6 \%)$ & $2.2 \%(10.3 \%)$ & $1.1 \%(5.1 \%)$ & $10.6 \%(5.6 \%)$ \\
\hline & $\begin{array}{l}\text { Controlled Non-Mastery } \\
\text { Recovering }\end{array}$ & $7.9 \%(28.6 \%)$ & $3.8 \%(14.9 \%)$ & $4.9 \%(23.1 \%)$ & $4.9 \%(23.1 \%)$ & $22.4 \%(5.6 \%)$ \\
\hline & Moderately Unplugged & $3.4 \%(12.2 \%)$ & $3.8 \%(14.9 \%)$ & $1.1 \%(5.1 \%)$ & $2.2 \%(10.3 \%)$ & $10.6 \%(4.1 \%)$ \\
\hline & Non-Mastery Recovering & $11.3 \%(40.8 \%)$ & $11.3 \%(44.7 \%)$ & $11.5 \%(53.9 \%)$ & $10.3 \%(48.7 \%)$ & $47.0 \%(5.6 \%)$ \\
\hline & Unplugged & $0.6 \%(2.0 \%)$ & $3.8 \%(14.9 \%)$ & $1.6 \%(7.7 \%)$ & $2.7 \%(12.8 \%)$ & $9.4 \%(5.7 \%)$ \\
\hline & Total & $27.7 \%(100 \%)$ & $25.3 \%(100 \%)$ & $21.3 \%(100 \%)$ & $21.2 \%(100 \%)$ & \\
\hline \multicolumn{7}{|l|}{ Unplugged } \\
\hline & Plugged In & $0.0 \%(0.0 \%)$ & $0.0 \%(0.0 \%)$ & $0.0 \%(0.0 \%)$ & $1.1 \%(18.2 \%)$ & $4.6 \%(9.1 \%)$ \\
\hline & $\begin{array}{l}\text { Controlled Non-Mastery } \\
\text { Recovering }\end{array}$ & $0.6 \%(11.1 \%)$ & $0.0 \%(0 \%)$ & $0.6(7.1 \%)$ & $0.5 \%(9.1 \%)$ & $6.8 \%(4.8 \%)$ \\
\hline & Moderately Unplugged & $1.7 \%(33.3 \%)$ & $2.2 \%(33.3 \%)$ & $2.7 \%(35.7 \%)$ & $1.6 \%(27.3 \%)$ & $32.4 \%(3.6 \%)$ \\
\hline & Non-Mastery Recovering & $0.6 \%(11.1 \%)$ & $1.6 \%(25.0 \%)$ & $2.7 \%(35.7 \%)$ & $0.5 \%(9.1 \%)$ & $20.2 \%(12.5 \%)$ \\
\hline & Unplugged & $2.3 \%(44.4 \%)$ & $2.7 \%(41.6 \%)$ & $1.6 \%(21.4 \%)$ & $2.2 \%(36.4 \%)$ & $36.0 \%(10.3 \%)$ \\
\hline & Total & $5.1 \%(100 \%)$ & $6.0 \%(100 \%)$ & $8.0 \%(100 \% 0$ & $6.0 \%(100 \%)$ & \\
\hline
\end{tabular}

Note. Due to missing data, the sample sizes assessing patterns of profile membership across consecutive days varied ( $n$ = 177-186). Percentages were calculated based on the sample size of participants who provided data for two consecutive days; discrepancies in the total values are attributed to rounding errors. Averages were calculated based on the percentage of employees in the specific pair of daily recovery profiles, out of those employees who belonged to the target profile on day $t$; standard deviations are reported in parentheses. 


\section{Table 7}

Three-Step Results for Antecedents (R3STEP; Research Question 3)

\begin{tabular}{|c|c|c|c|c|c|c|c|c|c|c|c|c|c|c|c|c|c|c|c|c|c|}
\hline & \multicolumn{3}{|c|}{$\begin{array}{l}\text { Plugged In } v . \\
\text { Controlled Non- } \\
\text { Mastery Recovering }\end{array}$} & \multicolumn{3}{|c|}{$\begin{array}{l}\text { Plugged In } v . \\
\text { Moderately } \\
\text { Unplugged }\end{array}$} & \multicolumn{3}{|c|}{$\begin{array}{l}\text { Plugged In v. } \\
\text { Non-Mastery } \\
\text { Recovering }\end{array}$} & \multicolumn{3}{|c|}{$\begin{array}{c}\text { Plugged In } v . \\
\text { Unplugged }\end{array}$} & \multicolumn{3}{|c|}{$\begin{array}{l}\text { Controlled Non- } \\
\text { Mastery Recovering v. } \\
\text { Moderately Unplugged }\end{array}$} & \multicolumn{3}{|c|}{$\begin{array}{l}\text { Controlled Non- } \\
\text { Mastery Recovering v. } \\
\text { Non-Mastery } \\
\text { Recovering }\end{array}$} & \multicolumn{3}{|c|}{$\begin{array}{c}\text { Controlled Non- } \\
\text { Mastery Recovering v } \\
\text { Unplugged }\end{array}$} \\
\hline & Coef. & SE & OR & Coef. & SE & OR & Coef. & SE & OR & Coef. & SE & OR & Coef. & SE & OR & Coef. & SE & OR & Coef. & SE & OR \\
\hline Role Ambiguity & -.04 & .20 & 1.04 & .32 & .22 & 1.38 & $.45^{\dagger}$ & .23 & 1.57 & $1.33^{* *}$ & .42 & 3.78 & $.35^{\dagger}$ & .20 & 1.42 & $.48^{*}$ & .20 & 1.62 & $1.37^{* *}$ & .42 & 3.94 \\
\hline Time Pressure & $.26^{\dagger}$ & .15 & 1.30 & .13 & .15 & 1.14 & $.70^{* *}$ & .16 & 2.01 & $.54^{*}$ & .22 & 1.72 & -.14 & .14 & 1.15 & $.44^{* *}$ & .14 & 1.55 & .28 & .20 & 1.32 \\
\hline \multirow[t]{3}{*}{ Social Support } & -.10 & .16 & 1.11 & .05 & .14 & 1.05 & -.05 & .17 & 1.05 & -.16 & .22 & 1.17 & .15 & .16 & 1.16 & .05 & .15 & 1.05 & -.05 & .19 & 1.05 \\
\hline & \multicolumn{3}{|c|}{$\begin{array}{c}\text { Moderately Unplugged } \\
v . \\
\text { Non-Mastery } \\
\text { Recovering }\end{array}$} & \multicolumn{3}{|c|}{$\begin{array}{c}\text { Moderately } \\
\text { Unplugged } v . \\
\text { Unplugged }\end{array}$} & \multicolumn{3}{|c|}{$\begin{array}{l}\text { Non-Mastery } \\
\text { Recovering v. } \\
\text { Unplugged }\end{array}$} & & & & & & & & & & & & \\
\hline & Coef. & SE & OR & Coef. & SE & OR & Coef. & SE & OR & & & & & & & & & & & & \\
\hline Role Ambiguity & .13 & .23 & 1.14 & $1.02^{*}$ & .44 & 2.77 & $.89^{*}$ & .42 & 2.44 & & & & & & & & & & & & \\
\hline Time Pressure & $.58^{* *}$ & .16 & 1.79 & $.41^{\dagger}$ & .21 & 1.51 & -.17 & .20 & 1.19 & & & & & & & & & & & & \\
\hline Social Support & -.09 & .17 & 1.09 & -.20 & .22 & 1.22 & -.11 & .20 & 1.12 & & & & & & & & & & & & \\
\hline
\end{tabular}

Note. $N=697$ (after accounting for lagged data). Coef. $=$ the estimate $(\beta)$ from the R3STEP multinomial logistic regression analysis, which uses listwise deletion; SE = standard error of the coefficient; OR = odds ratio. Positive coefficient values indicate that higher values on the antecedent make a person more likely to be in the first latent profile, of the two latent profiles being compared; negative values indicate that higher values on the antecedent make a person more likely to be in the second latent profile compared. Job demands (i.e., role ambiguity and time pressure) and resources (i.e., social support) were modeled during the afternoon of the prior workday $(t-1)$, with profiles of daily recovery experiences during the morning of day $t$.

${ }^{\dagger} p<.10 ;{ }^{*} p<.05 ;{ }^{* *} p<.01$. 


\section{Table 8}

Three-Step Results for Distal Outcomes (BCH; Research Question 4)

\begin{tabular}{|c|c|c|c|c|c|c|}
\hline & $\begin{array}{c}\text { Plugged In } \\
(A)\end{array}$ & $\begin{array}{c}\text { Controlled Non- } \\
\text { Mastery Recovering } \\
(B)\end{array}$ & $\begin{array}{l}\text { Moderately } \\
\text { Unplugged } \\
(C) \\
\end{array}$ & $\begin{array}{l}\text { Non-Mastery } \\
\text { Recovering } \\
\text { (D) }\end{array}$ & $\begin{array}{c}\text { Unplugged } \\
(E)\end{array}$ & $\begin{array}{c}\text { Chi-Square } \\
\left(\chi^{2}\right) \\
\end{array}$ \\
\hline \multicolumn{7}{|l|}{ Next-Day Morning } \\
\hline Sleep Quality & $2.81^{\mathrm{B}, \mathrm{C}, \mathrm{D}, \mathrm{E}}$ & $3.14^{\mathrm{A}, \mathrm{D}, \mathrm{E}}$ & $3.32^{\mathrm{A}, \mathrm{D}}$ & $3.77^{\mathrm{A}, \mathrm{B}, \mathrm{C}}$ & $3.66^{\mathrm{A}, \mathrm{B}}$ & $87.20^{* *}$ \\
\hline Emotional Exhaustion & $2.69^{\mathrm{B}, \mathrm{C}, \mathrm{D}, \mathrm{E}}$ & $2.17^{\mathrm{A}, \mathrm{D}, \mathrm{E}}$ & $1.97^{\mathrm{A}}$ & $1.71^{\mathrm{A}, \mathrm{B}}$ & $1.57^{\mathrm{A}, \mathrm{B}}$ & $43.69^{\text {** }}$ \\
\hline \multicolumn{7}{|l|}{ Next-Day Afternoon } \\
\hline Emotional Exhaustion & $2.74^{\mathrm{B}, \mathrm{C}, \mathrm{D}, \mathrm{E}}$ & $2.23^{\mathrm{A}, \mathrm{E}}$ & $2.22^{\mathrm{A}, \mathrm{E}}$ & $1.93^{\mathrm{A}, \mathrm{E}}$ & $1.52^{\mathrm{A}, \mathrm{B}, \mathrm{C}, \mathrm{D}}$ & $37.68^{* *}$ \\
\hline Engagement & $3.23^{\mathrm{C}, \mathrm{E}}$ & $3.20^{\mathrm{C}, \mathrm{E}}$ & $3.63^{\mathrm{A}, \mathrm{B}, \mathrm{D}}$ & $3.22^{\mathrm{C}, \mathrm{E}}$ & $4.01^{\mathrm{A}, \mathrm{B}, \mathrm{D}}$ & $33.13^{* *}$ \\
\hline Helping Behavior & $3.08^{\mathrm{E}}$ & $3.05^{\mathrm{E}}$ & $3.35^{\mathrm{D}}$ & $2.86^{\mathrm{C}, \mathrm{E}}$ & $3.54^{\mathrm{A}, \mathrm{B}, \mathrm{D}}$ & $11.98^{*}$ \\
\hline Personal Initiative & $3.49^{\mathrm{E}}$ & $3.40^{\mathrm{E}}$ & $3.65^{\mathrm{D}}$ & $3.29^{\mathrm{C}, \mathrm{E}}$ & $4.06^{\mathrm{A}, \mathrm{B}, \mathrm{D}}$ & $16.60^{* *}$ \\
\hline
\end{tabular}

Note. $N=967$. The BCH procedure in Mplus uses full information maximum likelihood estimation. The values per outcome are means. The chi-squared value reflects the significance of the omnibus difference test. The pairwise comparisons are highlighted through the superscripts, indicating profiles that are significantly different at least at $p<.05$ within each row.

${ }^{*} p<.05{ }^{* *} p<.01$. 


\section{Table 9}

Multilevel Regression Results (Supplemental Analyses)

\begin{tabular}{|c|c|c|c|c|c|c|c|c|c|c|c|c|}
\hline \multirow[t]{2}{*}{ Dependent variable } & \multicolumn{2}{|c|}{$\begin{array}{c}\text { Sleep Quality } \\
(A M)\end{array}$} & \multicolumn{2}{|c|}{$\begin{array}{c}\text { Emotional Exhaustion } \\
(A M)\end{array}$} & \multicolumn{2}{|c|}{$\begin{array}{c}\text { Emotional Exhaustion } \\
(P M)\end{array}$} & \multicolumn{2}{|c|}{$\begin{array}{c}\text { Engagement } \\
(P M)\end{array}$} & \multicolumn{2}{|c|}{$\begin{array}{c}\text { Helping Behavior } \\
(P M)\end{array}$} & \multicolumn{2}{|c|}{$\begin{array}{c}\text { Personal Initiative } \\
(P M)\end{array}$} \\
\hline & $\gamma$ & SE & $\gamma$ & SE & $\gamma$ & SE & $\gamma$ & SE & $\gamma$ & $\mathrm{SE}$ & $\gamma$ & SE \\
\hline Intercept & $3.28^{* *}$ & .04 & $2.09^{* *}$ & .06 & $2.21^{* *}$ & .07 & $3.35^{* *}$ & .04 & $3.11^{* *}$ & .06 & $3.49^{* *}$ & .05 \\
\hline Psychological Detachment & .07 & .05 & -.09 & .07 & -.04 & .04 & .01 & .03 & -.05 & .03 & -.01 & .03 \\
\hline Relaxation & $.20^{* *}$ & .04 & -.04 & .18 & .02 & .04 & -.03 & .03 & .03 & .03 & .02 & .04 \\
\hline Mastery & $-.08^{*}$ & .04 & -.05 & .04 & -.05 & .03 & $.06^{*}$ & .03 & -.02 & .03 & .03 & .03 \\
\hline Control & $.10^{*}$ & .04 & -.10 & .26 & -.01 & .04 & .01 & .03 & $.07 \dagger$ & .04 & $-.06^{\dagger}$ & .03 \\
\hline
\end{tabular}

Note. Level $1 n=891-967$. Level $2 n=207$. All analyses were at the within-person level of analysis (Level 1); predictors were withinperson centered and modeled as random.

${ }^{\dagger} p<.10 ;{ }^{*} p<.05 ;{ }^{* *} p<.01$. 


\section{Figure 1}

Elbow Plot for BIC and C-AIC in Determining Profile Solution

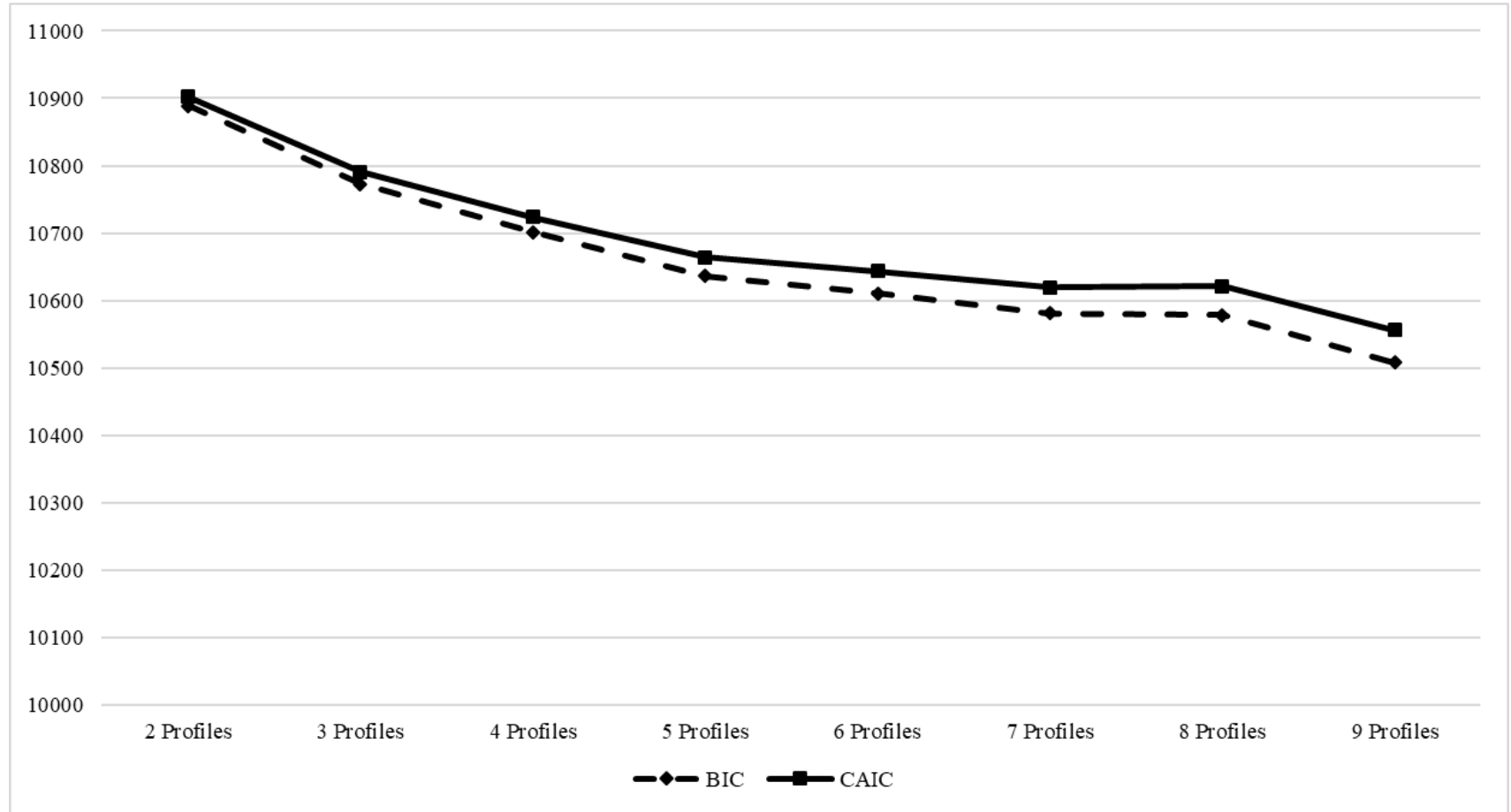

Note . $\mathrm{BIC}=$ Bayesian information criterion $; \mathrm{C}-\mathrm{AIC}=$ consistent Akaike information criterion (calculated as the BIC value plus the number of free parameters). 


\section{Figure 2}

Latent Profiles of Daily Recovery Experiences

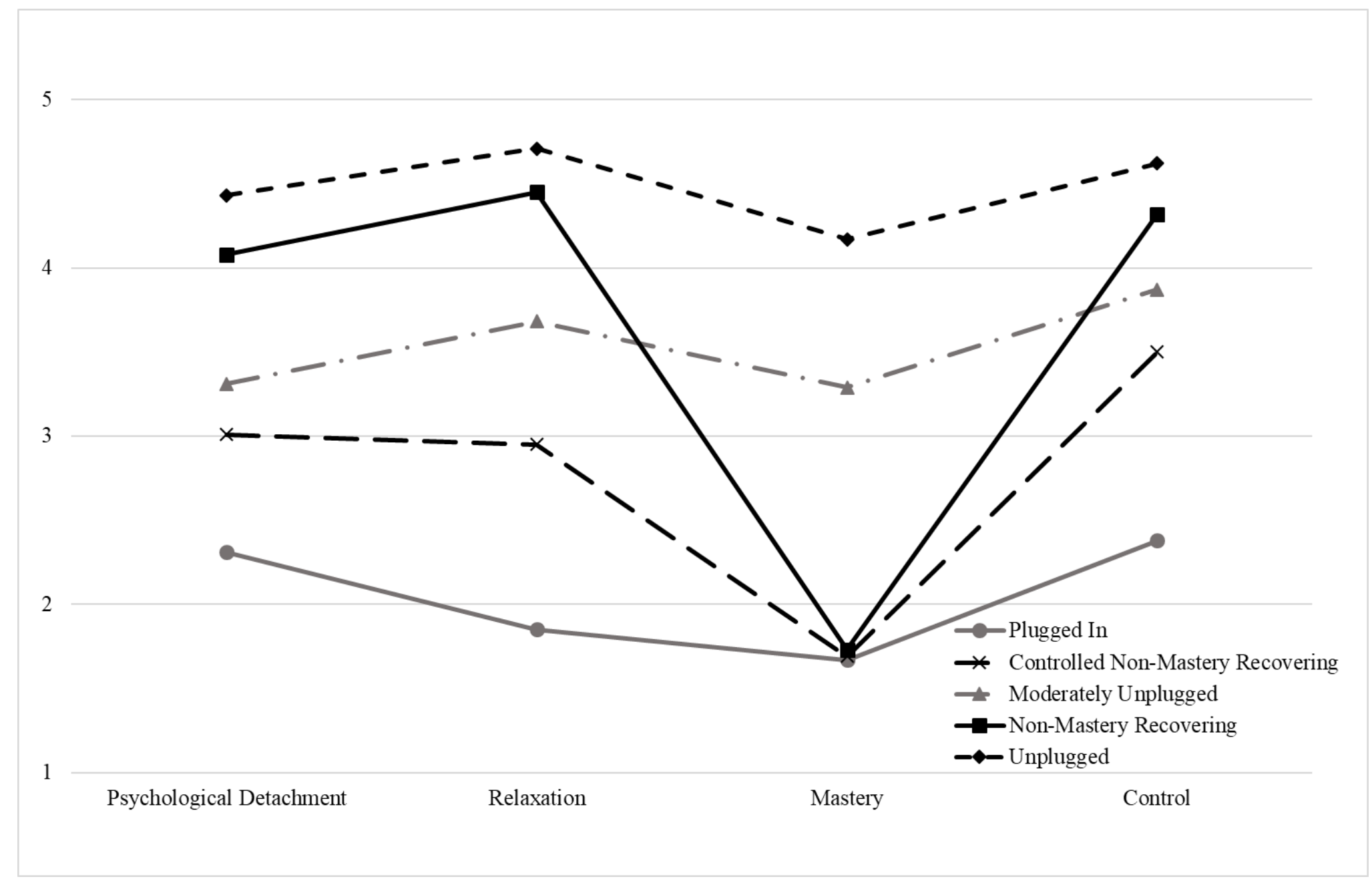

Note. The $y$-axis refers to participants' level of each of the recovery experiences $(1=$ not at all; $5=$ very much $)$. 